\title{
Implementing a physical initialization procedure in a regional spectral model: impact on the short-range rainfall forecasting over South America
}

\author{
By A. M. B. NUNES ${ }^{1, *}$ and S. COCKE ${ }^{2}$, ${ }^{1}$ Centro de Previsão do Tempo e Estudos Climáticos, Instituto \\ Nacional de Pesquisas Espaciais, Cachoeira Paulista, SP 12630, Brazil; ${ }^{2}$ Center for Ocean-Atmospheric Prediction \\ Studies, Florida State University, Tallahassee, FL 32306, USA
}

(Manuscript received 28 May 2002; in final form 15 October 2003)

\begin{abstract}
In this paper we describe the implementation of a physical initialization procedure in the recently developed Florida State University nested regional spectral model, and its impact on short-term forecasting over South America. Because the regional model forecasts perturbations to the global model results, we seek to determine the impact of the boundary condition on the regional model assimilation. The regional model is able to assimilate the satellite-derived rain rates rather well, regardless of whether the global model, providing the boundary conditions, has been physically initialized. The regional model is able to assimilate higher-resolution precipitation data, and also the global model assimilates coarser resolution data as reported in earlier studies. Ten experiments are performed over the northern part of South America during the tropical rainy season of January and February 1999. The initial correlation coefficients of the rain rates exceed 0.9 for all physically initialized cases. The subsequent $24-\mathrm{h}$ forecast is also improved, as measured by spatial correlation coefficients and equitable threat scores.
\end{abstract}

\section{Introduction}

The use of primitive equation models has led to the 'initialization problem', because these models are less restrictive and allow that inertia-gravity modes have their amplitudes (energy) spuriously amplified. To provide an initialized data set for numerical weather prediction models, procedures of initialization have been designed. These initialization techniques can be 'static', in which the data are adjusted to externally imposed dynamical constraints at a fixed time, or 'dynamic', where the forecast model produces the initial condition (Daley, 1991).

The most successful static initialization method used for global spectral models is the nonlinear normal mode initialization (NNMI). In NNMI, the eigenfunctions may be divided into slow (Rossby) and fast (inertia-gravity) modes, in such a way that a specific mode can be filtered. This was tested in its linear form by Williamson (1976), including nonlinear terms by Machenhauer (1976, 1977), Baer and Tribbia (1977), and with physical parametrizations by Kitade (1983).

*Corresponding author.

Current affiliation: Scripps Institution of Oceanography at University of California, San Diego La Jolla, CA 92093-0224, USA.

e-mail: anunes@ucsd.edu.
The four-dimensional variational (4DVar) assimilation (e.g. Lewis and Deber, 1985; Navon et al., 1992) can be considered a procedure of initialization as well, and it is a dynamic method where the data are assimilated over time. In the 4DVar technique, a version of the forecast model and its adjoint (a conjugate transpose of the model) are taken to variationally minimize the difference between the observations and model forecasts, incorporating objective analysis and initialization (Daley, 1991).

Another dynamic method, the digital filtering initialization (DFI), has been shown to be more efficient in removing inertiagravity modes from the initial data than NNMI. The DFI uses digital filter theory (see Hamming, 1989) to suppress highfrequency noise acting directly on a time series provided by the numerical model integration, and does not require any information about Rossby and gravity modes structures as in normal mode initialization procedures (Huang et al., 1994). In the DFI, forward and backward integrations are performed using a digital filter around an initial time. These forward and backward integrations can be adiabatic, i.e. without the diabatic processes and the horizontal diffusion (Lynch and Huang, 1992). In diabatic DFI, the forward integration includes diabatic processes (Huang and Lynch, 1993). A recursive filter, which depends on the previous output values, can also be applied during the backward adiabatic and the forward diabatic integrations; this is called recursive 
adiabatic-diabatic DFI (Lynch and Huang, 1994). However, the utilization of a non-recursive digital filter during both (adiabatic backward and diabatic forward) integrations is less expensive and has the same effectiveness in suppressing undesirable high-frequency oscillations as earlier schemes (Lynch et al., 1997).

Polavarapu et al., (2000) discussed a 4DVar data assimilation for controlling gravity waves using a strong or weak constraint by means of a non-recursive digital filter. The concept of strong and weak constraints has been introduced by Sasaki (1970), and means that a balanced initial state can be enforced exactly (strong) or approximately (weak) for providing the best fit with the analysis.

Rainfall prediction in the tropical region remains one of the most challenging problems in weather forecasting. Numerical models often do not reproduce the correct rain rate even at the start of the forecast, despite using analyses which have been produced by sophisticated data assimilation schemes. The problem may be due in part to the lack of observational data, especially for moisture and divergence in sparsely populated tropical regions. Another problem might be that the forecasting model uses a different cumulus parametrization than that of the analysis model. Furthermore, most models tend to undergo 'spin-up' during the first 24 hours of integration. A number of techniques have been proposed to improve the analysis of the moisture and divergence fields, such as Donner (1988), Heckley et al. (1990), Puri and Miller (1990), Puri and Davidson (1992), Aonashi (1993) and Kasahara et al. (1994). Among those techniques, the physical initialization (PI) procedure (Krishnamurti et al., 1984, 1988, 1991, 1994; Treadon 1996), where the diabatic effects are included through rainfall assimilation or diabatic heating (Manobianco et al., 1994), has been shown to dramatically increase the nowcasting skill of precipitation, with a subsequent improvement in the one-day forecast. The PI technique assimilates observed precipitation (often satellite-derived) using a reverse cumulus algorithm, along with reverse algorithms for other physical processes.

The PI procedure, which is a dynamic method as well, could be considered as a low-cost 4DVar but without its disadvantages, such as those mentioned in Haase et al. (2000): ‘...the great computational costs and the complex inversion of the nonlinear processes (e.g. the parametrization of precipitation) in an adjoint model.' However, studies where the assimilation of precipitation was incorporated in a variational data assimilation system have been performed: Fillion and Errico (1997) and Marècal and Mahfouf (2000), both using the one-dimensional variational (1DVar) framework, and Županski and Mesinger (1995), Zou and Kuo (1996) and Tsuyuki (1997), using 4DVar. Hou et al. (2000) discussed the impact of the precipitation assimilation on climate studies. They defined a 1+1D assimilation procedure, which consists in a time integration of a simplified column version of an atmospheric general circulation model with full physics. This scheme assimilates satellite rain rate and total precipitation water estimates into a continuous time integration.

At present, there have been limited attempts at incorporating PI in a regional model. Yap (1995) implemented PI in the Florida State University (FSU) regional grid point model. PI in a regional model introduces additional challenges to that of global models due to the impact of the lateral boundaries on the assimilation. Because PI typically uses a 24-h assimilation period, the lateral boundary may exert significant influence into the interior domain, thus affecting assimilation.

In this paper we describe the implementation and performance of PI in the recently developed FSU nested regional spectral model (FSUNRSM). This model differs in many aspects from the FSU grid point model; in particular, the regional spectral model computes perturbations to the FSU global spectral model (or other driving model) and uses the spectral technique for computing the horizontal derivatives of the perturbations and solving the semi-implicit algorithm. In the regional spectral model, the 'boundary' conditions are provided throughout the regional domain, thus it raises interesting additional questions about the assimilation of data in the presence of such a boundary condition. It is shown here that the FSUNRSM is quite able to assimilate the observed precipitation rain rate, with initial rain rate correlation coefficients exceeding 0.9 . Such a high degree of assimilation was not demonstrated in Yap (1995), although the reasons for this are not clear. The regional domain chosen for this study is the northern part of South America during the rainy months of January and February in the Amazon region. Station data are sparse in this tropical region, so one relies solely on Special Sensor Microwave/Imager (SSM/I) Outgoing Longwave Radiation (OLR) derived rainfall estimates for precipitation assimilation and verification.

In Section 1, we introduce the models used in this study and the satellite-derived precipitation data used for the rain rate assimilation and forecast verification. In Section 2 we describe the PI procedure. In Section 3 we discuss the experimental results of PI assimilation and 24-h accumulated precipitation forecast over South America. Section 4 has some concluding remarks and suggestions for future work.

\section{Methodology}

\subsection{Model}

The FSU global spectral model (FSUGSM) and the FSUNRSM are the global and regional models involved in this study, respectively. The FSUGSM is a spectral primitive equation model and for this study uses a triangular spectral truncation of 106 waves (T106). Details of the FSUGSM are given in Krishnamurti et al. (1991) and Cocke and LaRow (2000). The FSUNRSM is a limited area spectral model, which is nested (one-way) in the FSUGSM. The FSUNRSM forecasts perturbations to the global 
model solution. The perturbations are represented spectrally by double trigonometric Fourier series. Thus, the FSUGSM provides the base or 'boundary' conditions throughout the regional domain. These base fields, along with the horizontal derivatives, are spectrally transformed to the regional model grid. The perturbations are relaxed to zero at the lateral boundaries so that the regional solution connects smoothly with the global solution. The perturbations evolve unconstrained in the interior of the domain, so the primary influence of the global model on the regional model solution is at the lateral boundaries. A more complete description of the model is given in Cocke (1998) and Cocke and LaRow (2000). The regional and global models share the same physics and vertical structure. Two convection schemes were used in this study: a Kuo scheme (Kuo, 1974), which was modified by Krishnamurti et al., (1983) and a simplified version (Pan and Wu, 1994) of the Arakawa-Schubert scheme (Arakawa and Schubert, 1974). The vertical coordinate is a $\sigma$-coordinate with 14 vertical levels. The regional model uses a Mercator projection (true at equator) with a resolution of about $48 \mathrm{~km}$ at $30^{\circ} \mathrm{S}$. The domain used is approximately $38^{\circ} \mathrm{S}$ to $8^{\circ} \mathrm{N}$ and $85^{\circ} \mathrm{W}$ to $21^{\circ} \mathrm{W}$.

\subsection{Data}

The analyses of wind, temperature, humidity and surface pressure for initializing the models are 0.5-degree European Centre for Medium Range Weather Forecasts (ECMWF) analyses valid at 12 UTC for a selected number of days during the Amazon wet season in January and February 1999. The arbitrarily chosen dates are 5, 11, 17 and 25 January, and 4, 11, 14, 17, 21 and 23 February. These dates refer to the start of the forecast (end of the assimilation period) and they are denoted as cases 1-10, respectively.

The rain rates used for data assimilation and verification are obtained from the SSM/I radiometer measurements from satellites launched by the Defense Meteorological Satellite Program (DMSP). The National Oceanic and Atmospheric Administration (NOAA)/National Environmental Satellite, Data, and Information Service (NESDIS) SSM/I algorithm (Ferraro and Marks, 1995) was used to estimate the rain rates based on scattered and emitted radiation received at four frequencies: 19, 22, 37 and $85 \mathrm{GHz}$. The algorithm distinguishes between land and ocean. Scattering over land is used to determine whether there is possible rain. Checks are made to determine if there is snow, desert or arid soil present, and if so then no rain is indicated. Over ocean, both scattered and emitted signals are used to determine rain rates. If sea ice is identified, then no rain is indicated. In the absence of SSM/I data, then rain rates estimates from NESDIS OLR measurements are used and blended into the rainfall data set (Gairola and Krishnamurti, 1992; Arkin, 1979).

The satellite estimates obtained by the above procedure yield 24-h accumulations. These estimates are then linearly interpo- lated in time to obtain rain rates at the global and regional model time-steps, respectively, 600 and $180 \mathrm{~s}$. At first glance, it might appear that this linear interpolation would interfere with the diurnal cycle. However, the model rain rates are only modified when the Kuo scheme establishes the convection, i.e. it is not forced by the procedure. The rain rate data, which were provided in a Gaussian grid of about $0.7^{\circ}$ resolution, are also bi-linearly interpolated to the global Gaussian grid of $1.125^{\circ}$ resolution (between $40^{\circ} \mathrm{S}$ and $40^{\circ} \mathrm{N}$ ) and the regional model Mercator projection of about $0.5^{\circ}$ resolution for its entire domain.

\subsection{Physical initialization}

The PI procedure described in this paper consists of three basic components: rainfall nudging, surface flux nudging and dynamic nudging. The major contribution for this procedure is due to the specific humidity vertical profile adjustment or rainfall nudging (Nunes, 2002), which is split into two reverse algorithms: deep convection and large-scale rainfall. Marècal and Mahfouf (2000) concluded, using 1DVar assimilation of satellite-derived rain rates, that increments of temperature with respect to the background state are small indicating that 1DVar essentially adjusts specific humidity to modify the precipitation amounts.' Their results basically agree with the goal of the rainfall nudging, which adjusts the humidity profiles and, so, the model forecasts the precipitation fields and their associated changes on the temperature profiles.

The initialization is performed over a 24 -h pre-integration period of the model to allow sufficient time to spin up the divergent field associated with the assimilated convective heating. Day -1 will refer to the start time of the initialization and Day 0 to the end of the integration and start of the forecast. This procedure is described in detail in Krishnamurti et al. (1984, 1988, 1991) for a global spectral model, and its application in Krishnamurti et al. (1993, 1994, 1995). However, a few modifications were made during its implementation in the regional spectral model.

2.3.1. Rainfall nudging. The rainfall nudging is defined by an analytical expression, which modifies the humidity vertical profile as a function of the observed and the predicted rain rates, in such a way that model rain is brought closer to the observed rain rate. A simple vertical structure function based on Krishnamurti et al. $(1988,1991)$ is used for the modified moisture:

$q_{\mathrm{m}}=\frac{R_{\mathrm{o}}}{R_{\mathrm{p}}} q+\frac{(1 / g) \int_{\sigma_{\mathrm{t}}}^{\sigma_{\mathrm{b}}} q \mathrm{~d} \sigma}{(1 / g) \int_{\sigma_{\mathrm{t}}}^{\sigma_{\mathrm{b}}} \mathrm{d} \sigma}\left(1-\frac{R_{\mathrm{o}}}{R_{\mathrm{p}}}\right)$

Here, $q_{\mathrm{m}}$ is the modified specific humidity, $q$ is the specific humidity before PI, $R_{\mathrm{o}}$ and $R_{\mathrm{p}}$ are the observed and predicted rainfall rates, and $\sigma_{\mathrm{b}}$ and $\sigma_{\mathrm{t}}$ denote the $\sigma$ levels at the base and top of the clouds, respectively. The saturation value of $q$ is imposed as a limit to $q_{\mathrm{m}}$. To obtain eq. (1) some constraints are 
(a)

FSUGSM PI \& FSUNRSM PI

24-hr Accumulated Precipitation (mm) Initial Condition: 1999-2-4 - 12 UTC

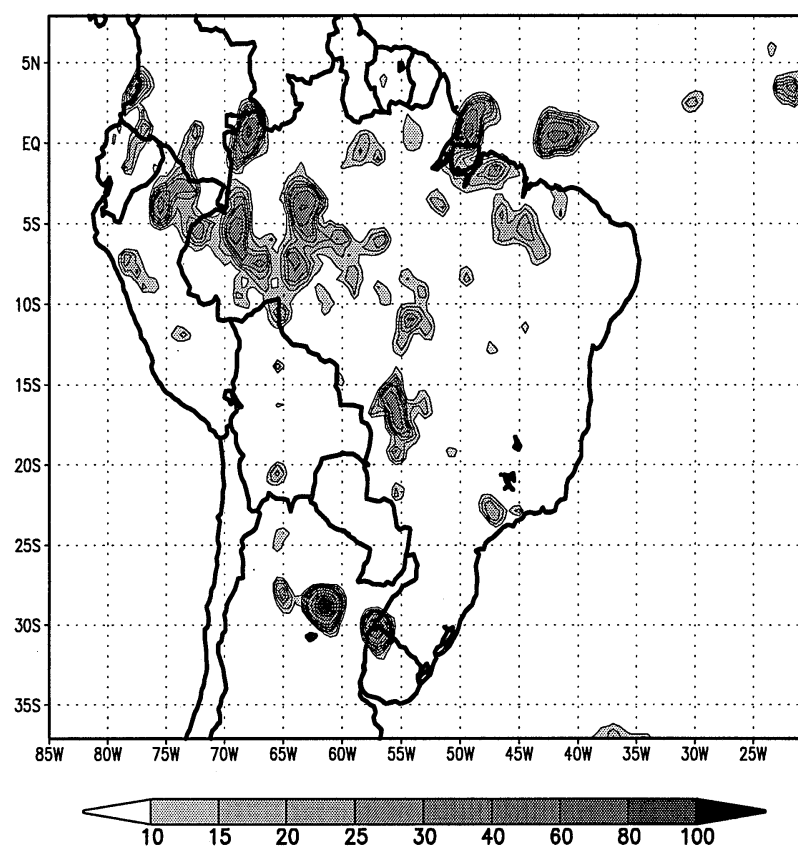

(c)

FSUGSM PI \& FSUNRSM NoPI 24-hr Accumulated Precipitation (mm) Initial Condition: 1999-2-4 - 12 UTC

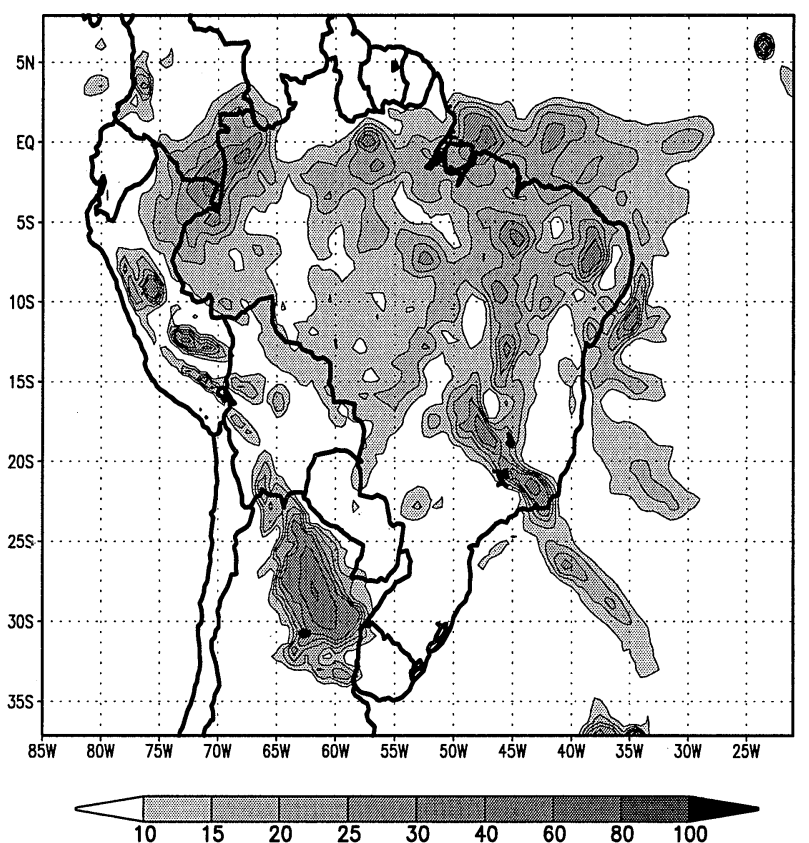

(b)

FSUGSM NoPI \& FSUNRSM PI 24-hr Accumulated Precipitation (mm) Initial Condition: 1999-2-4 - 12 UTC

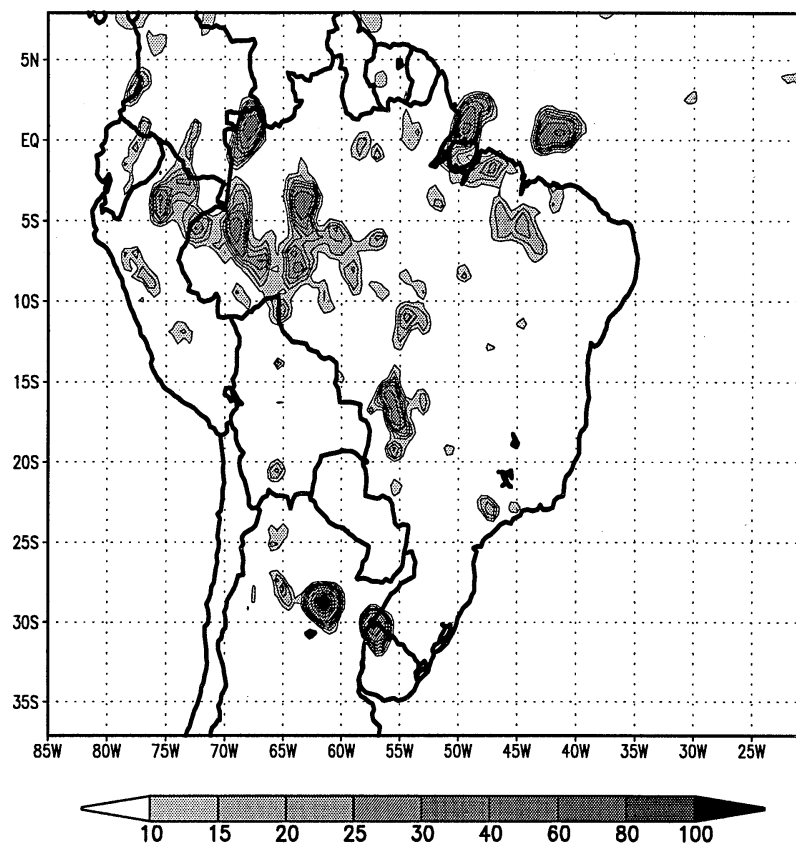

(d) SSMI/OLR Rainfall Estimation 24-hr Accumulated Precipitation (mm)

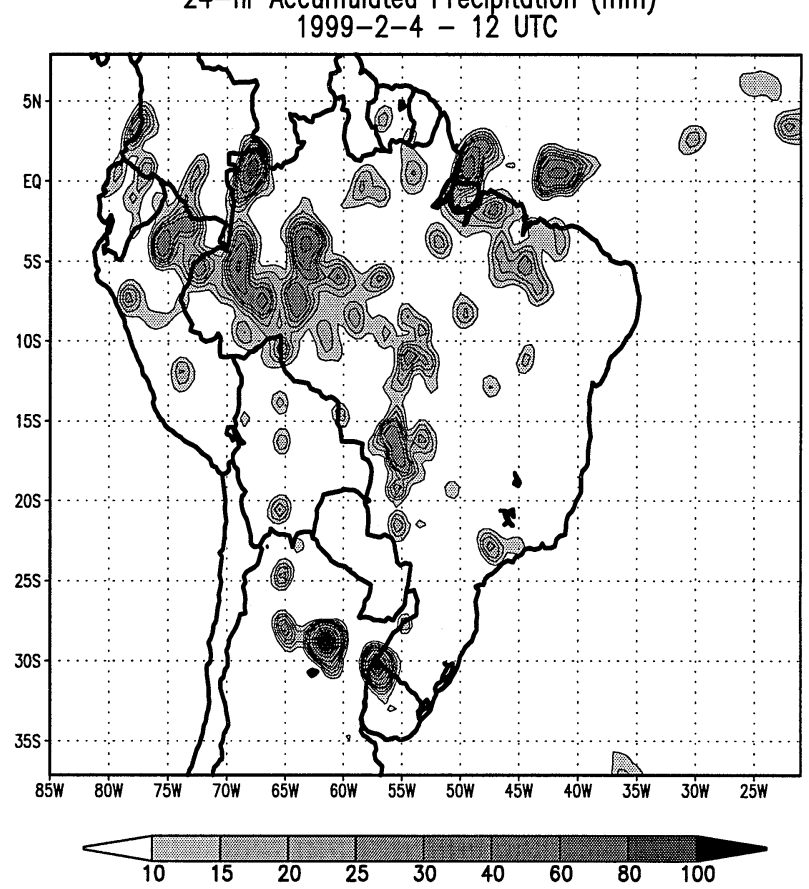

Fig. 1. 24-h accumulated precipitation (mm) valid at 4 February 1999, 12 UTC: (a) FSUGSM PI and FSUNRSM PI; (b) FSUGSM NoPI and FSUNRSM PI; (c) FSUGSM PI and FSUNRSM NoPI; (d) SSM/I-OLR estimate. 


\section{Accumulated Precipitation during Initialization}

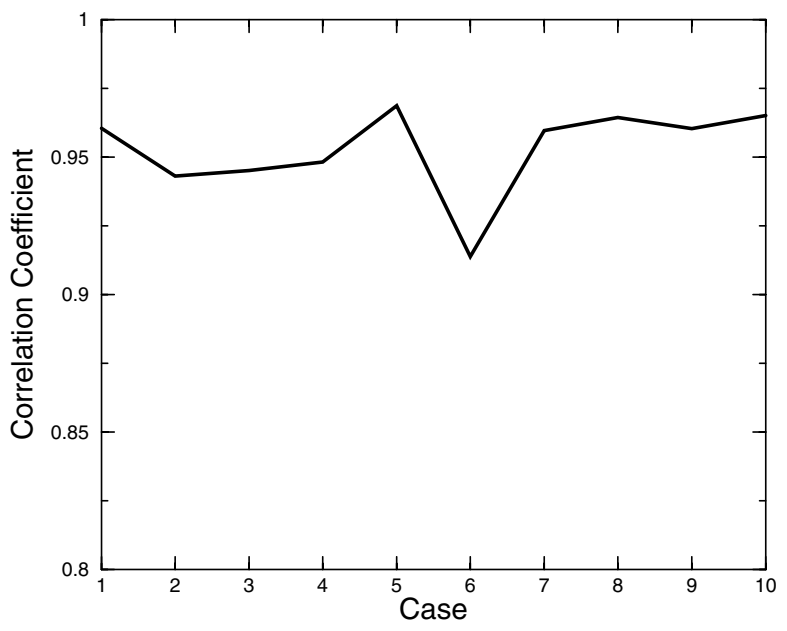

Fig. 2. Spatial correlation coefficients of accumulated precipitation during the FSUNRSM initialization period.

required: (a) the total precipitable water is kept constant during the PI procedure; and (b) the modified moisture convergence is proportional to the observed rainfall. The first constraint determines that the scheme can modify the vertical humidity profile, but cannot add mass to the column. The second is related to cumulus parametrization modified by Krishnamurti et al. (1983) where the main contribution to rainfall is moisture convergence, and the advection terms are neglected.

For more complicated convection schemes, an iterative procedure can be used as in Treadon (1996). In the current scheme, rainfall is only initialized in regions where the modified Kuo scheme (see Krishnamurti et al., 1983 for details) indicates convective instability in the model. In other words, rainfall regions are essentially defined by two requirements: conditional instability and moisture convergence. The rainfall nudging is not done unless the observed or model rain rates exceed $10 \mathrm{~mm} \mathrm{~d}^{-1}$.

Although the satellite-derived precipitation algorithm used here does not distinguish between convective and stable (largescale) rainfall, a similar vertical structure function is also applied for non-convective rain. Non-convective rain is determined by the model's large-scale precipitation parametrization. Following the deep convection nudging, the large-scale parametrization (Kanamitsu, 1975) first determines the nonconvective rain amounts, then the vertical structure function adjusts the specific humidity profiles, when the ratio between the observed and the model rain rates exceeds a pre-determined value.

2.3.2. Surface flux nudging. Tropical convection is strongly forced by boundary layer processes, particularly the fluxes of sensible $\left(Q_{\mathrm{s}}\right)$ and latent $\left(Q_{1}\right)$ heat. The vertically integrated moisture sink is closely related to the evaporation and precipitation.
Given the fluxes that are needed to maintain convection, it is possible to determine the values of temperature and humidity in the boundary layer that provide those fluxes through a 'reverse similarity' algorithm described in Krishnamurti et al. (1991). However, the version of the PI scheme implemented here parametrizes the variation of the sensible and latent heat due to the changing of the precipitation rate through the rainfall nudging, and only in the places where the precipitation amounts were changed by this nudging.

The following energy balance equation (Anthes et al., 1987) is only used during the assimilation period to update $T_{\mathrm{g}}$ after the rainfall nudging

$\frac{\partial T_{\mathrm{g}}}{\partial t}=Q^{*}+Q_{\mathrm{s}}+Q_{1}+Q_{\mathrm{g}}$,

where $Q^{*}$ represents the net solar radiation flux, and $Q_{\mathrm{g}}$ the ground flux.

2.3.3. Dynamic nudging. As model integration proceeds, the model state will drift from observed analyses. To minimize this drift, while still permitting assimilation, a Newtonian relaxation toward observed analyses is applied to the vorticity, divergence and surface pressure. The humidity and temperature are not relaxed in order to accommodate the appropriate heating and moistening rates associated with the assimilated convection. The divergence is nudged more weakly than the vorticity for the same reasons. Furthermore, the Newtonian relaxation or dynamic nudging allows a noise-free initial condition, demonstrated by early initialization and four-dimensional data assimilation schemes (e.g. Anthes, 1974; Hoke and Anthes, 1976; Ramamurthy and Carr, 1987).

The rainfall and surface flux nudging are performed in the same manner in both the regional and global models. The dynamic nudging procedure is modified to account for the perturbation nature of the regional model. The spectral nudging equation can be written (with the indices suppressed) as

$A(t+\Delta t)=\frac{A^{*}(t+\Delta t)+2 \Delta t N A_{0}(t+\Delta t)}{1+2 \Delta t N}$,

where $A$ is the dynamical variable being nudged, $A^{*}$ is the value of $A$ before nudging at time $(t+\Delta t), A_{0}$ is the prescribed value toward which $A$ is being nudged, and $N=N(A, t)$ is a nudging coefficient. In the global spectral model, $A$ is a spherical harmonic spectral coefficient of the dynamical variable and $A_{0}$ is the corresponding spectral coefficient of the observed analysis field, linearly interpolated in time to the time-step of the global model. In the regional spectral model, $A$ is also a spectral coefficient, in double Fourier space, of the model perturbation. The value $A_{0}$ is a spectral coefficient of the analysis perturbation, which is obtained by subtracting from the regional analysis the global base solution in which the regional model is nested at the appropriate analysis time. Thus, at the start of the initialization period or Day $-1, A_{0}$ is just the regional analysis 
minus the global analysis. The global and regional analyses in this case are taken from the same (ECMWF) analysis interpolated to the appropriate model resolution and orography. At the end of the initialization period, $A_{0}$ is the regional analysis at Day 0 minus the global (base) solution after 24-h integration (the initialization period). The nudging coefficients are the same as were used in previous PI studies with the global spectral model (Krishnamurti et al., 1988, 1991, 1994), i.e. $10^{-4} \mathrm{~s}^{-1}$, for the vorticity and the surface pressure, and $5 \times 10^{-5} \mathrm{~s}^{-1}$, for the divergence. No attempt has been made to determine if these coefficients are optimal for the regional model, but this should be investigated.

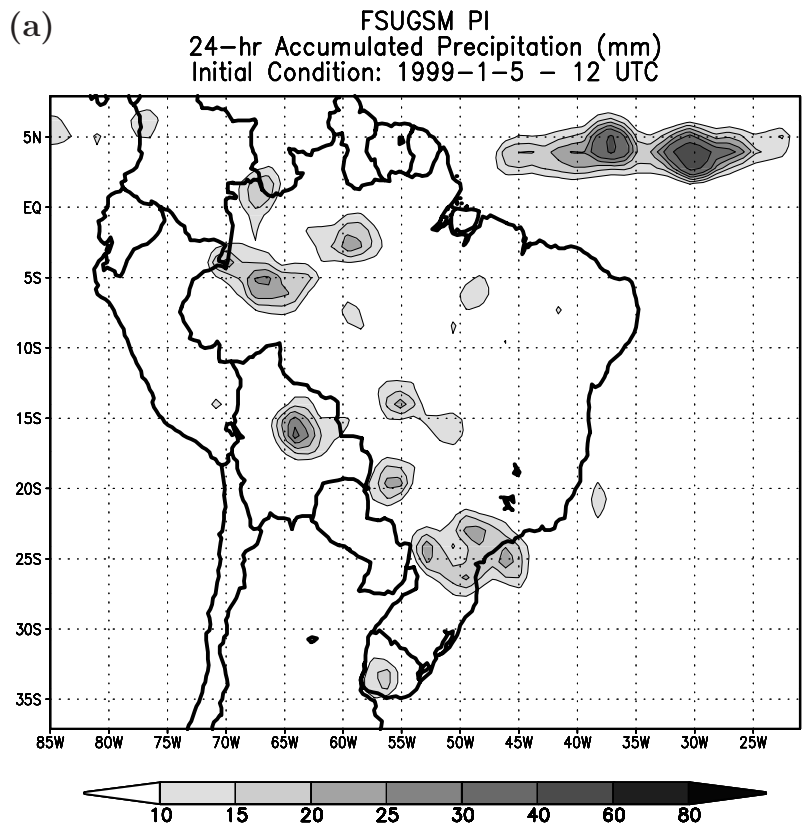

(b) SSMI/OLR Rainfall Estimation on FSUGSM resolution
24-hr Accumulated Precipitation ( $\mathrm{mm}$ )

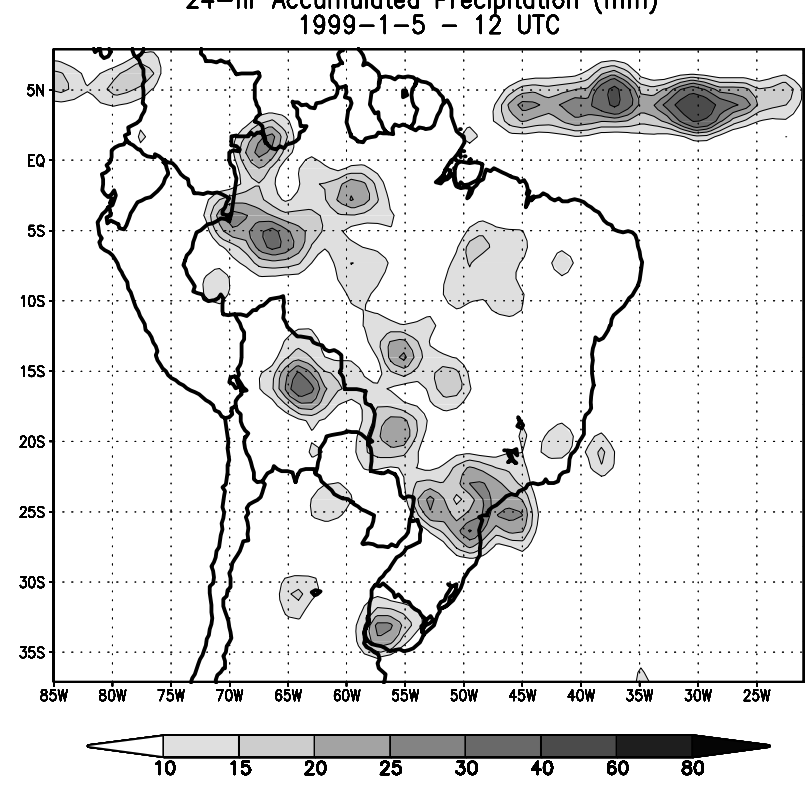

(d) SSMI/OLR Rainfall Estimation on FSUNRSM resolution 24-hr Accumulated Precipitation ( $\mathrm{mm}$ )

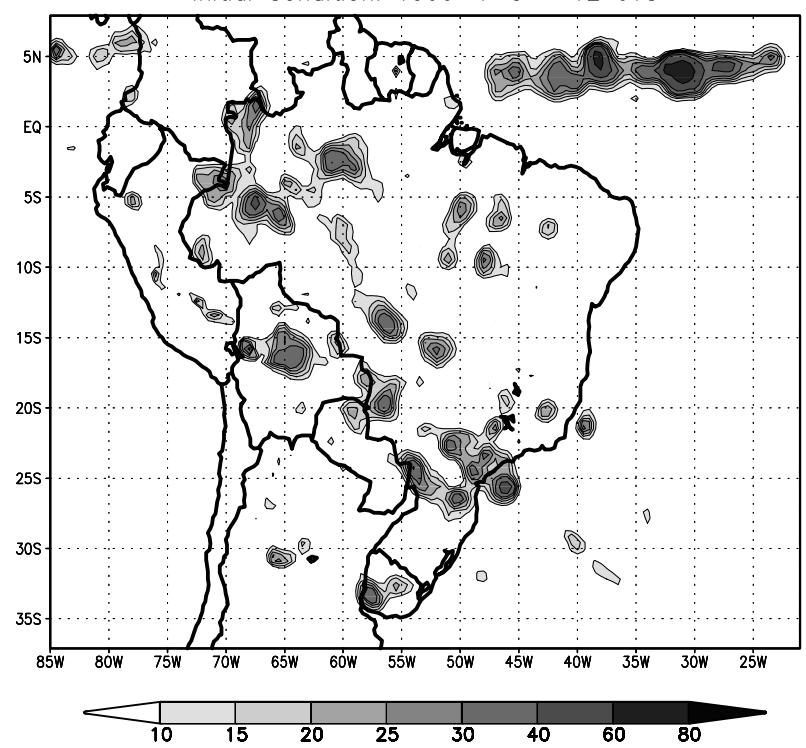
1999-1-5 - 12 UTC

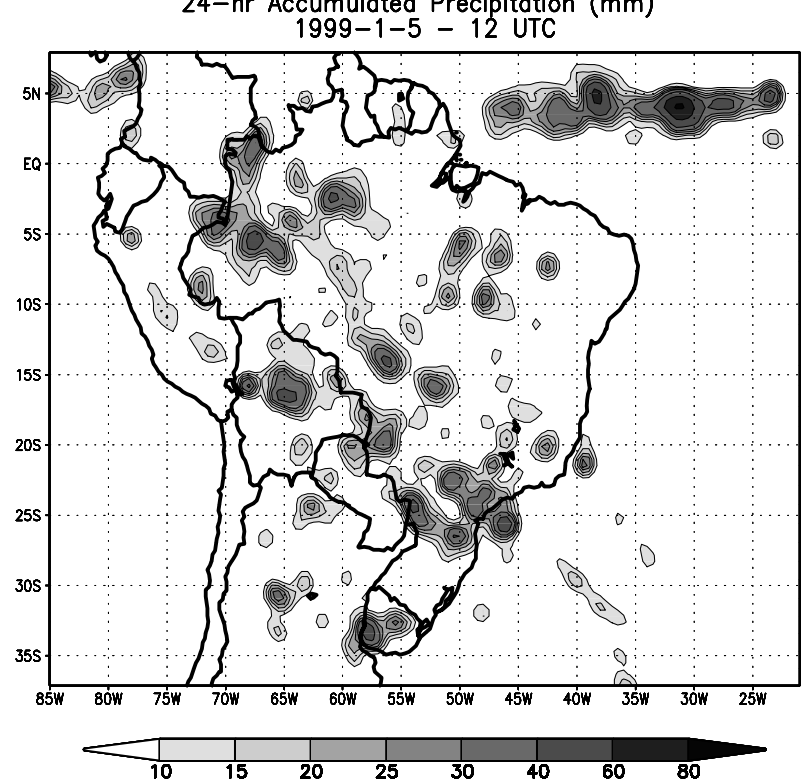

Fig. 3. 24-h accumulated precipitation (mm) valid at 5 January 1999, 12 UTC: (a) FSUGSM PI initial condition; (b) SSM/I-OLR estimate on FSUGSM resolution; (c) FSUNRSM PI initial condition; (d) SSM/I-OLR estimate on FSUNRSM resolution. 


\section{Experiments}

\subsection{Impact of the boundary conditions on the assimilation}

The 24-h integration period required by PI is long enough that the boundary conditions may have an impact on the precipitation assimilation. Furthermore, the FSUNRSM is different from most other regional models in that the 'boundary' conditions are provided throughout the domain, and not just at the lateral boundaries. To assess the boundary impact on precipitation assimilation, three simple experiments are performed: (i) both the global and regional model were physically initialized (Global PI + Reg PI); (ii) global model is integrated without PI but regional model with PI (Global NoPI + Reg PI); (iii) global model is integrated with PI and regional model without (Global PI + Reg NoPI).

A typical result for these three cases is shown in Fig. 1. This figure shows the accumulated precipitation during the initialization (assimilation) period. Fig. 1d shows the verifying precipitation. In both cases Global PI + Reg PI and Global NoPI + Reg PI, the model was able to assimilate the precipitation very well, with the Global PI + Reg PI doing slightly better. The correlations of the accumulated precipitation against the verifying analysis for the three cases are Global PI + Reg PI - 0.96, Global NoPI + Reg PI - 0.93 and Global PI + Reg NoPI 0.43 .

It has been found that using a physically initialized global base solution generally produces the best results, as might be expected because a better boundary condition has been used. This was more evident near the lateral boundaries, as expected. Nevertheless, the regional model was able to assimilate the precipitation fairly well even when the boundary conditions are not physically initialized. It can be seen from the cases Global PI + Reg NoPI and Global NoPI + Reg PI that the global base fields do not exert too strong an influence on the regional model solution in the interior of the domain, despite the imposition of the base fields throughout the domain. Thus, the perturbation may become large enough to allow the regional model solution to evolve differently from the global model solution.

Another test would be to use analysis for the boundary conditions. This was not done because the analyses were available only at 24-h intervals, which is a rather long interval to nest the regional model. However, we note that, in the case Global PI + Reg PI, the global solution was nudged toward analysis during the initialization period. Along with the fact that the correlation of the assimilated precipitation exceeds 0.9 , this indicates that we would probably not see much improvement using analysis boundary conditions.

\subsection{Impact on the precipitation assimilation}

Ten cases have been arbitrarily selected during the months of January and February 1999 in order to evaluate the performance of PI on the assimilation and forecast of tropical rainfall. These cases are chosen during the rainfall season of the Amazon region and the months where the South Atlantic Convergence Zone is more active as well. Based on the results of the previous section, PI was applied to both models for each of the 10 cases. Then, the 24-h accumulated precipitation forecasts of the physically initialized cases were compared with control experiments where no initialization was done. The control experiments start $24 \mathrm{~h}$ later than the PI, because there is no assimilation period.

The correlation coefficients of accumulated precipitation during the initialization period are shown in Fig. 2. All the correlation coefficients exceed 0.9 , indicating successful assimilation of precipitation. These results are consistent with results obtained with global model PI reported in Krishnamurti et al. (1994). Thus, the regional model with PI is able to assimilate fine-scale precipitation and also the global model assimilates precipitation with a coarser resolution. This is further illustrated in Fig. 3 where a plot of accumulated precipitation, during initialization, is shown for the global and regional models along with the verifying analyses for the respective resolutions for 5 January.

Other fields, such as temperature, are modified by the PI procedure. However, the model forecasts the precipitation after the changes in the vertical specific humidity profile producing consistent temperature profiles as well. Fig. 4 shows the temperature fields valid at 5 January 1999, 12 UTC, at 850- and 300-hPa levels for the FSUNRSM PI (Figs. 4a and b), and for the control experiment (Figs. $4 \mathrm{c}$ and d). The reanalyses of the National Centers for Environmental Prediction (NCEP) Department of Energy (DOE; Kanamitsu et al. (2002)) are used as an independent data set for verification (Figs. 4e and f) for the same date and pressure levels. The NCEP-DOE reanalyses (R-2) have the following horizontal and vertical resolutions: T62 $\left(1.875^{\circ}\right)$ and 28 levels.

Figure 5 shows the equitable threat score (ETS), as in Schaefer (1990), for the accumulated precipitation during the initialization period for the average of the 10 cases. As mentioned above, the models did not assimilate precipitation amounts below $10 \mathrm{~mm}$, and this accounts for the lower scores for the threats below that value. While the spatial correlation coefficients are very high, always above 0.9 , the threat scores indicate that further improvement is possible in the assimilation. The maximum possible threat score is 1.0 whereas the model obtained scores less than 0.6. The reason for this less-than-optimal assimilation is that the model has not undergone convection in regions where the model atmosphere is stable, despite the presence of rain indicated by the observed data. Thus, when the regional model is undergoing convection, the predicted rain rates can be matched reasonably well to the observed data, and convection can be suppressed if the observed data indicate no rain. However, if the model atmosphere is stable, then the rain rates cannot be matched in the current scheme. This could be remedied by introducing a convective heating term, which would cause the model atmosphere to become unstable. Such an approach was used in Yap (1995). This possibility is being investigated. 
(a) FSUNRSM + PI Initial Condition

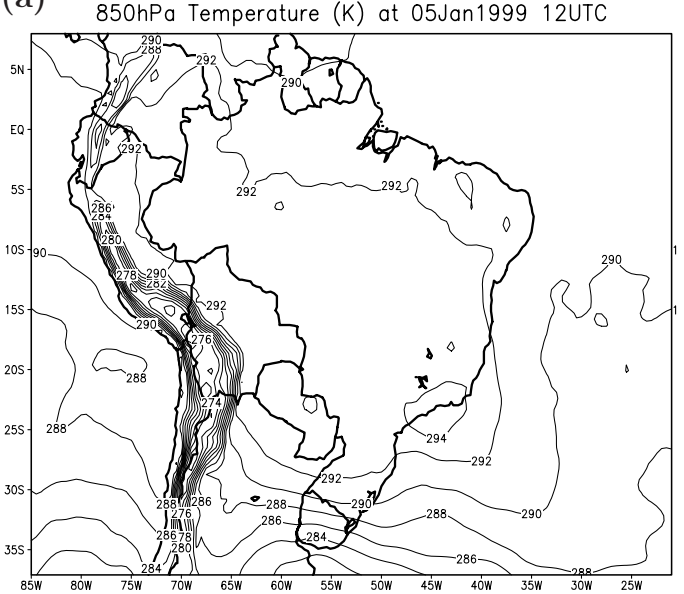

(c) FSUNRSM Initial Condition

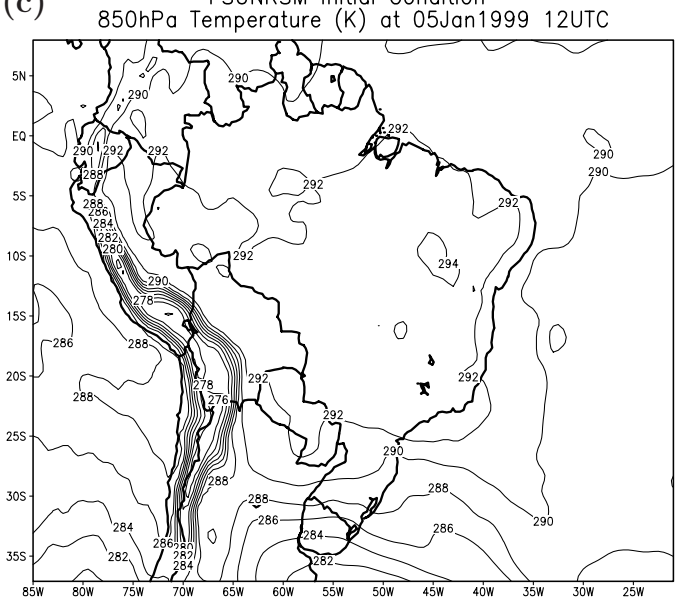

NCEP-DOE Reanalysis $(\mathrm{R}-2)$
(e) $850 \mathrm{hPa}$ Temperature $(\mathrm{K})$ at 05Jan1999 12UTC

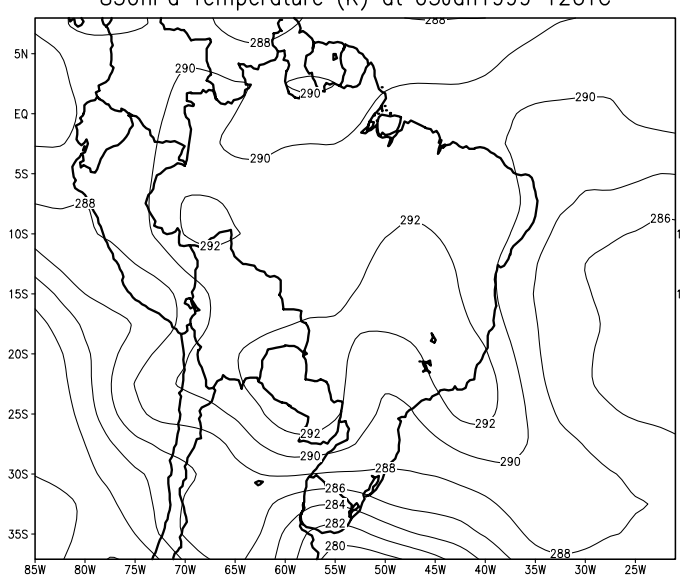

(b) FSUNRSM + PI Initial Condition

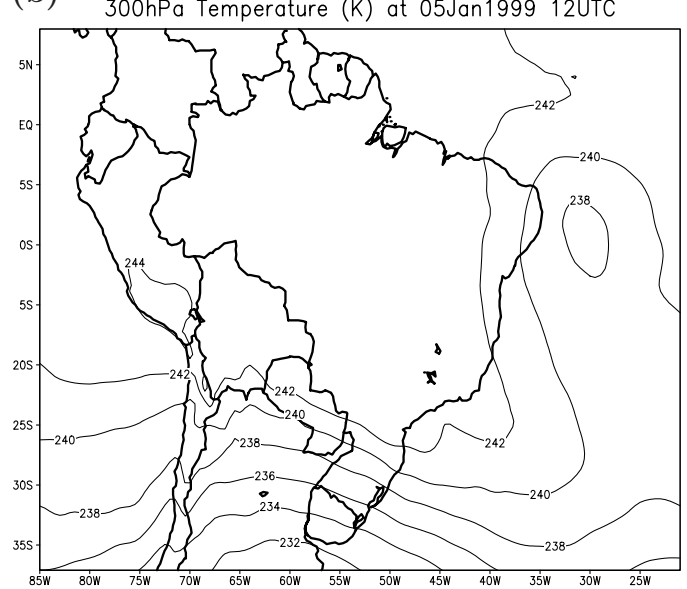

(d) FSUNRSM Initial Condition

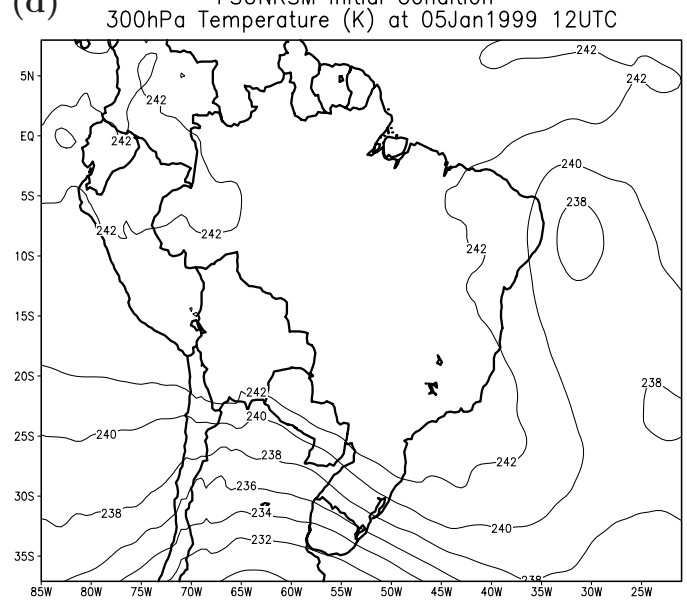

(f)

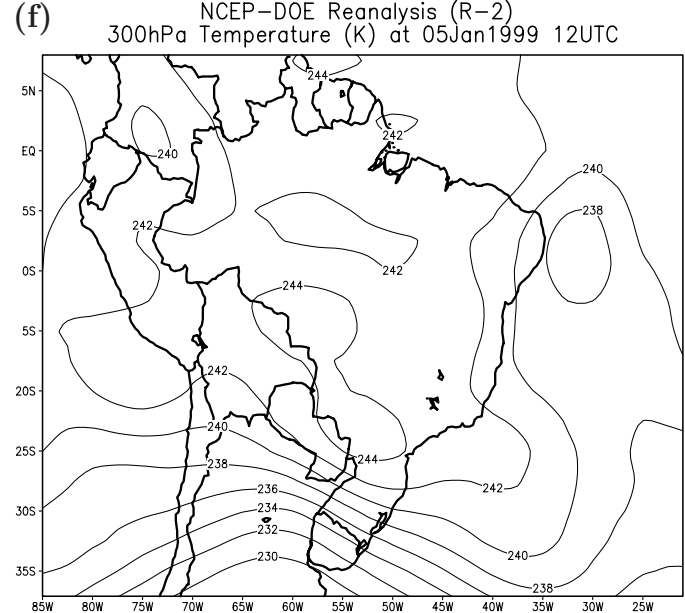

Fig. 4. Temperature (K) valid at 5 January 1999 at 12 UTC: for the FSUNRSM PI initial condition at (a) $850 \mathrm{hPa}$ and (b) $300 \mathrm{hPa}$; for the FSUNRSM control experiment at the initial time at (c) $850 \mathrm{hPa}$ and (d) $300 \mathrm{hPa}$; and for the NCEP-DOE reanalysis (R-2) at (e) $850 \mathrm{hPa}$ and (f) $300 \mathrm{hPa}$. 


\section{Precipitation during Initialization Period}

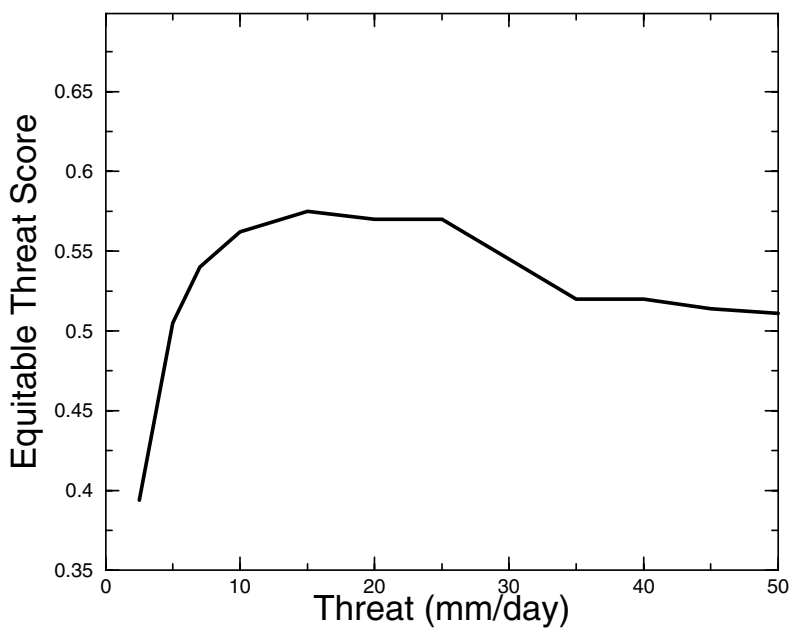

Fig. 5. Equitable threat scores of accumulated precipitation during the FSUNRSM initialization period.

Anyway, the ETS values using PI compare well with the results of Županski and Mesinger (1995) for a study case (6 June 1993 at 12 UTC), using 4DVar assimilation of the conventional and precipitation data, where the regional NCEP Eta is the forecast model.

\subsection{Impact on the short-term precipitation forecast}

The correlation coefficients of the 24-h forecast accumulated precipitation are shown in Fig. 6 for the regional model PI and control runs where no initialization was done. The PI correlation

\section{4-hour Precipitation Forecast}

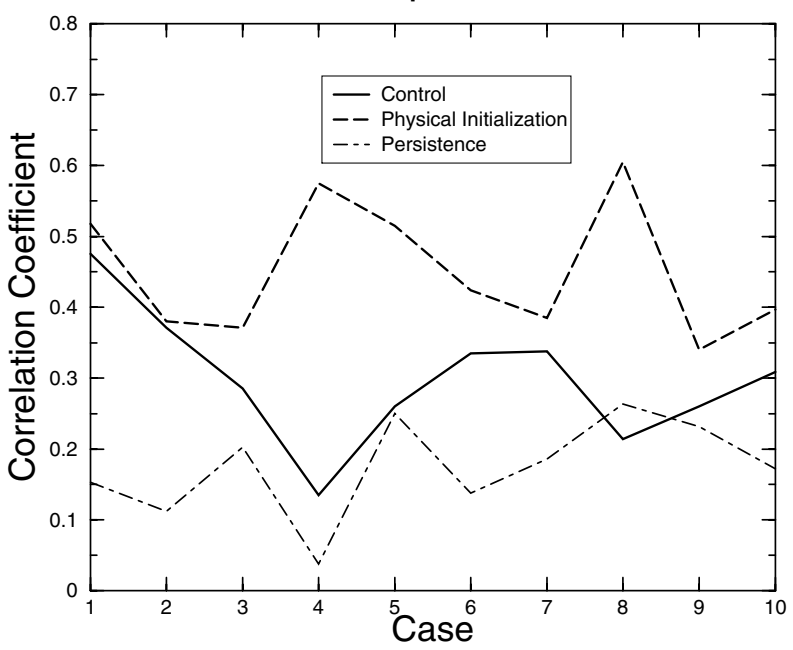

Fig. 6. Spatial correlation coefficients of 24-h accumulated precipitation forecast. Control experiments are represented by a solid line, PI by a dashed line, and persistence by a dot-dashed line.

\section{4-hour Precipitation Forecast}

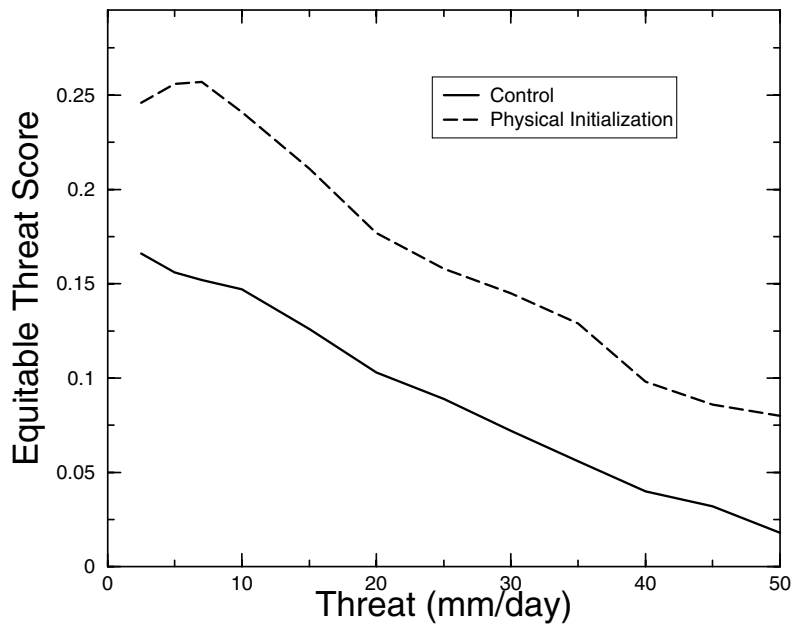

Fig. 7. Equitable threat scores of FSUNRSM 24-h accumulated precipitation forecast. Control experiments are represented by the solid line, and PI by the dashed line.

coefficients are consistently higher than the control as well as the persistence. Indeed, sometimes the PI correlation coefficients are highest when the control correlation coefficients are very low. The ETS for the PI and control experiments are shown in Fig. 7. Again, the scores for the PI experiments are substantially better than the control. PI reduces much of the 'drizzle' produced by the Kuo scheme, and increases the number of large rain events. Comparisons with Županski and Mesinger (1995) show a similar

\section{4-hour Precipitation Forecast Threat $>10 \mathrm{~mm} /$ day rain}

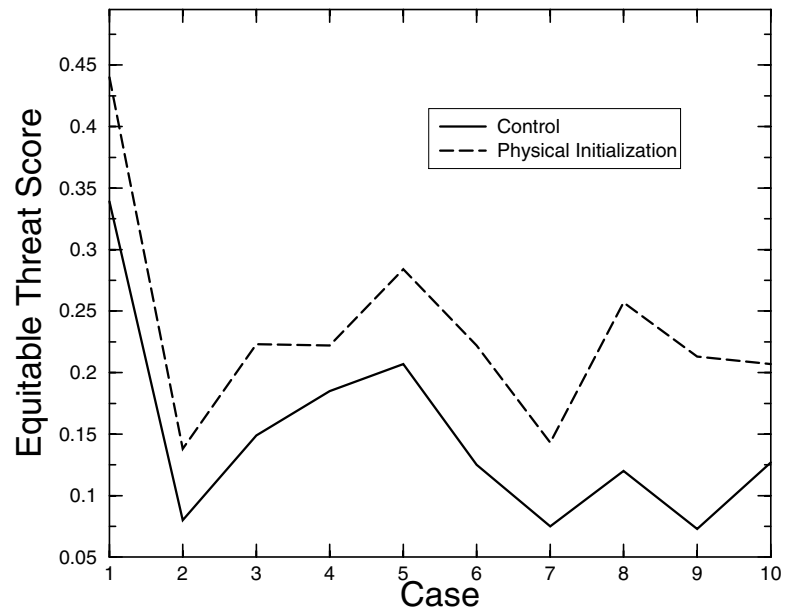

Fig. 8. Equitable threat scores of FSUNRSM 24-h accumulated precipitation forecast for threat $>10 \mathrm{~mm} \mathrm{~d}^{-1}$ rain. Control experiments are represented by a solid line, and PI by a dashed line. 
(a) FSUGSM PI \& FSUNRSM PI

24-hr Accumulated Precipitation (mm) Forecast valid at 1999-2-18-12 UTC

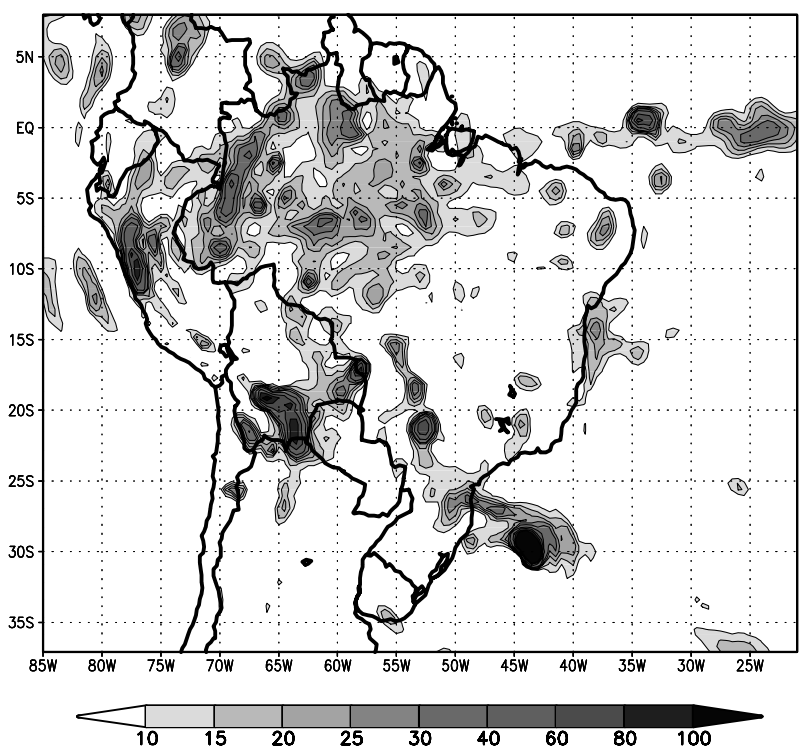

(b)

FSUGSM NOPI \& FSUNRSM NoPI 24-hr Accumulated Precipitation (mm) Forecast valid at 1999-2-18-12 UTC

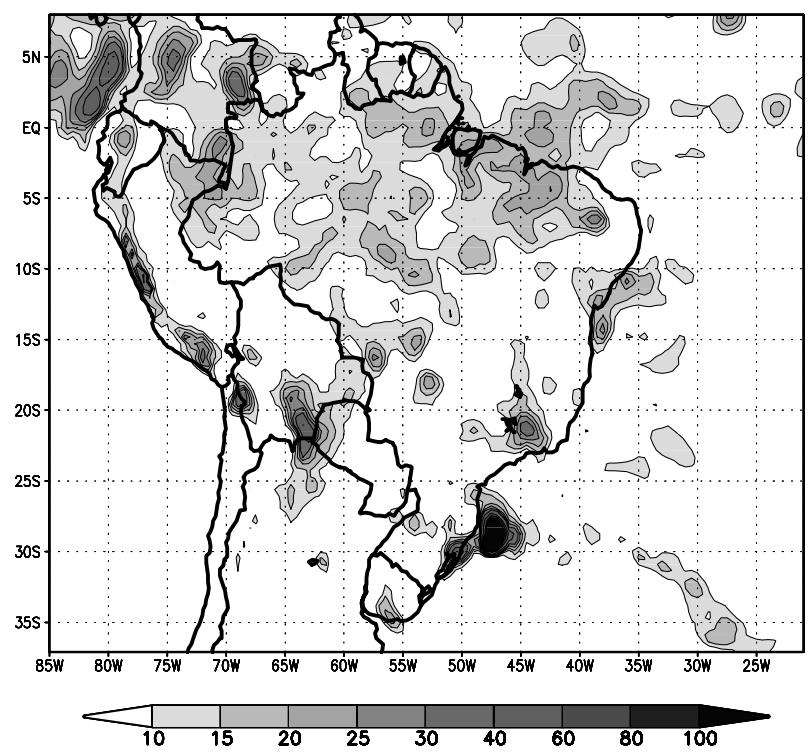

(c) SSMI/OLR Rainfall Estimation 24-hr Accumulated Precipitation (mm) 1999-2-18-12 UTC

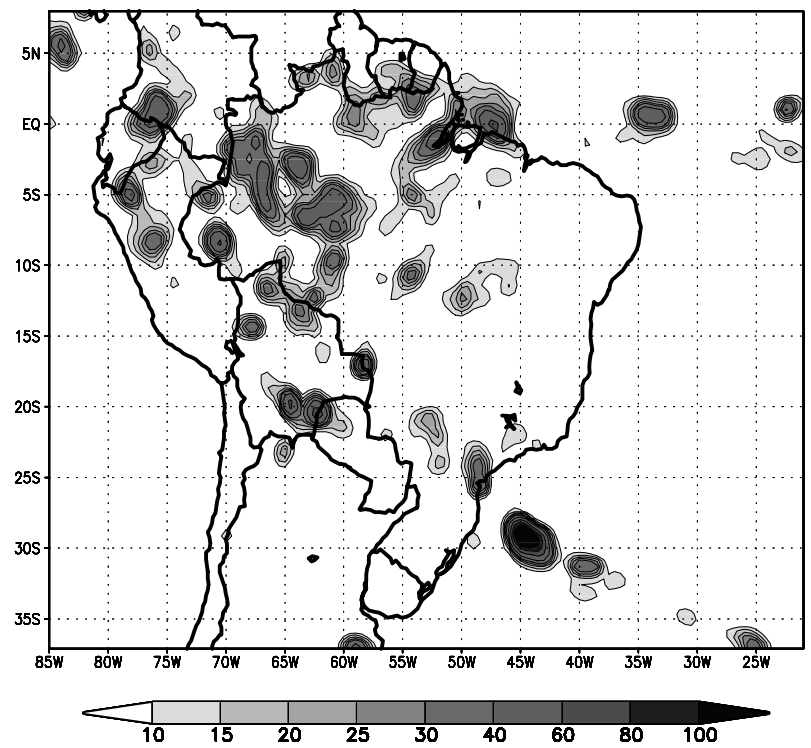

Fig. 9. 24-h accumulated precipitation (mm) valid at 18 February 1999, 12 UTC: (a) FSUNRSM PI 24-h forecast with FSUGSM PI as boundary condition; (b) FSUNRSM NoPI 24-h forecast with FSUGSM NoPI as boundary condition; (c) SSM/I-OLR estimate.

behavior with more realistic precipitation forecast for the experiment with precipitation assimilation except for their study case, the ETS values indicate that the experiments without precipitation assimilation outperformed that with precipitation assimilation at some threats. Figure 8 shows the $10 \mathrm{~mm} \mathrm{~d}^{-1}$ equitable threat scores for the PI and control experiments. In every case, the PI experiments outperformed the control. The improvement is even greater at larger threats (not shown). However, the ability to predict the precipitation amounts after the end of the assimilation period is most related to the model's performance.

A 24-h forecast valid at 18 February, 12 UTC is shown in Fig. 9. In the PI experiment, the model was able to forecast the intense precipitation in the western part of Brazil, as well as some of the heavier rain events in the Intertropical Convergence 
(a) FSUGSM PI \& FSUNRSM PI

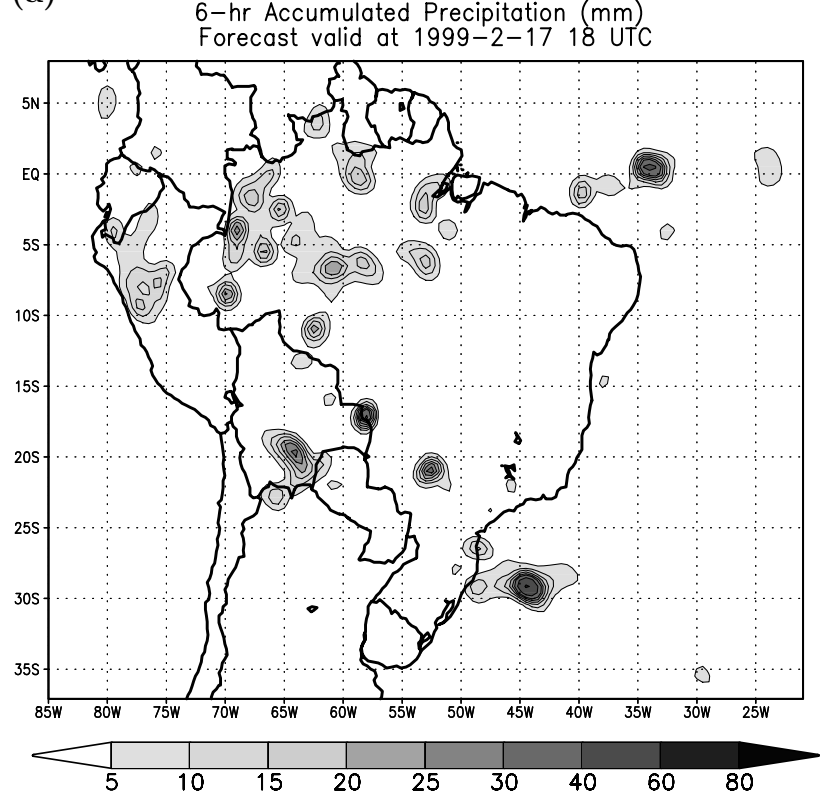

(c) $\quad$ FSUGSM PI \& FSUNRSM PI

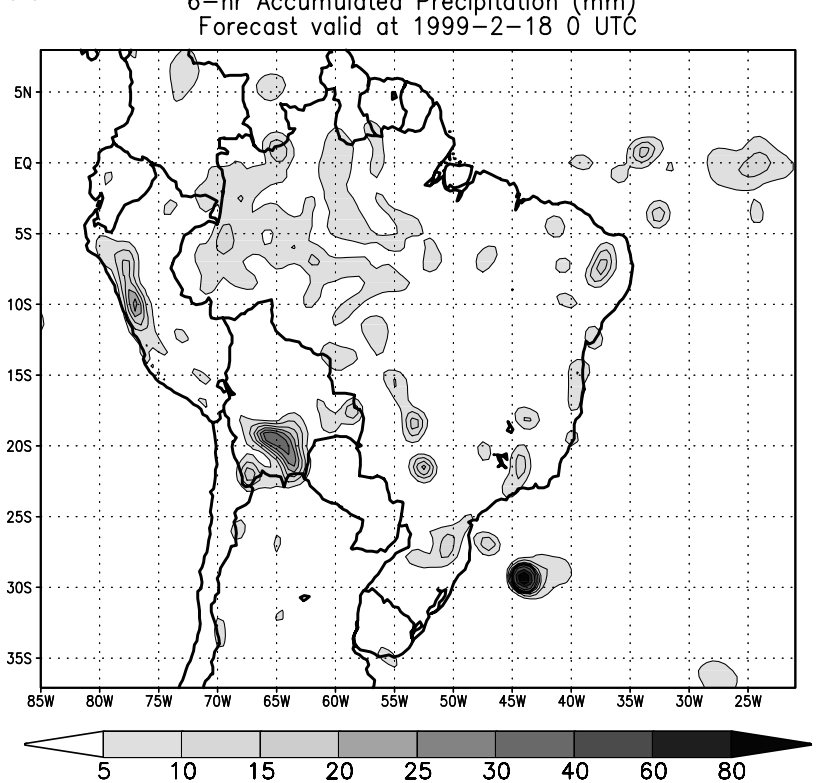

(b)

FSUGSM NoPI \& FSUNRSM NoPI 6 - $\mathrm{hr}$ Accumulated Precipitation ( $\mathrm{mm}$ ) Forecast valid at 1999-2-17 18 UTC

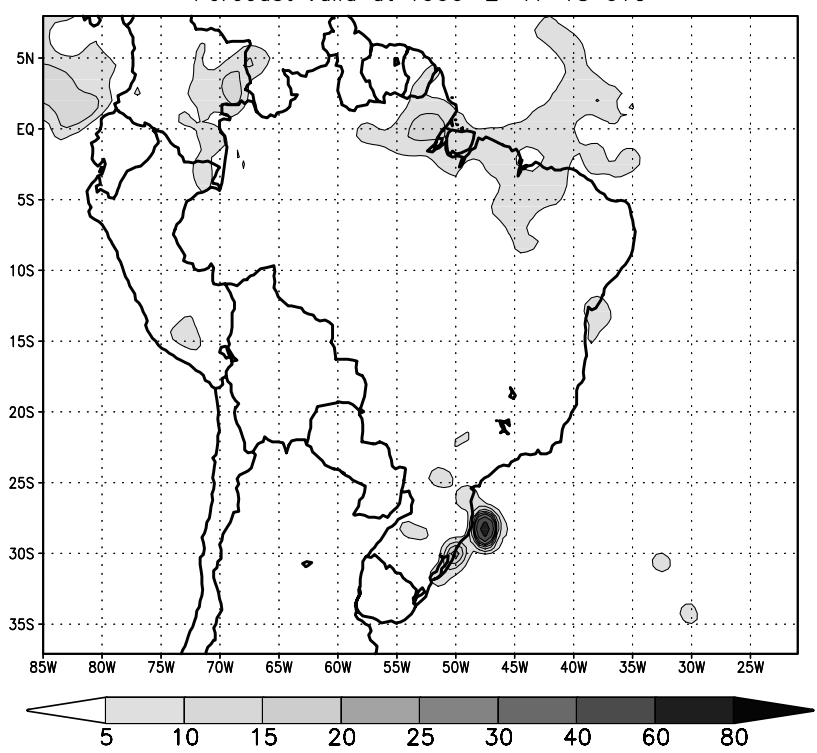

(d) FSUGSM NoPI \& FSUNRSM NoPI

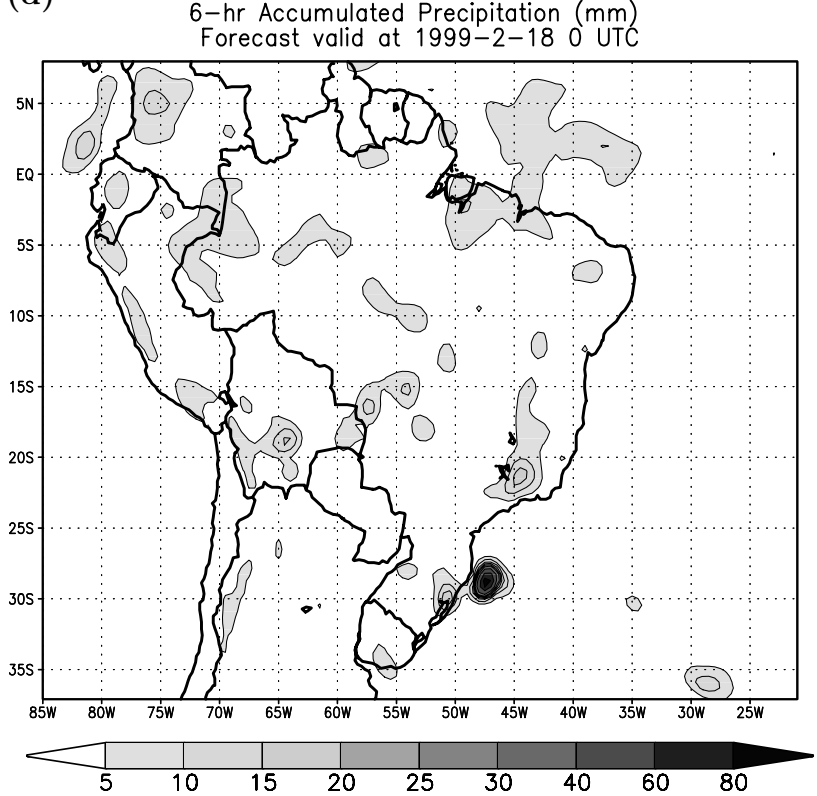

Fig. 10. FSUNRSM 6-h accumulated precipitation forecasts (mm) valid at 17 February 1999 at 18 UTC for (a) PI and (b) control, and at 18 February 1999 at 0 UTC for (c) PI and (d) control, where the FSUGSM PI provided the boundary conditions.

Zone (ITCZ) and off the southeast coast of Brazil. The control experiment tended to produce weaker and more widely spread precipitation. We have noted some problems in the model, such as the probably erroneous precipitation along the coastal regions.

To verify how long the PI procedure maintains its impact on the short-term forecast, the 12-h accumulated precipitation forecast for 18 February 1999 at 0 UTC was split into two 6-h accumulations for the PI (Figs. 10a and c) and control (Figs. 10b and d) ex- periments. The end of the assimilation period (17 February 1999 at 12 UTC) was not included in the first six hours of the precipitation accumulation. The rain core located in the southeast coast of Brazil was better placed in the PI 6-h accumulation plots than in the equivalent control plots, comparing to the SSM/I-OLR estimate (Fig. 9c). In the PI experiment, the rainfall related to the ITCZ was better displayed during the first six hours of the accumulation period (Fig. 10a), such as the rainfall over the Amazon 

FSUGSM PI \& FSUNRSM PI
3-hr Accumulated Precipitation (mm)
Forecast valid at $1999-2-17$ (15 UTC

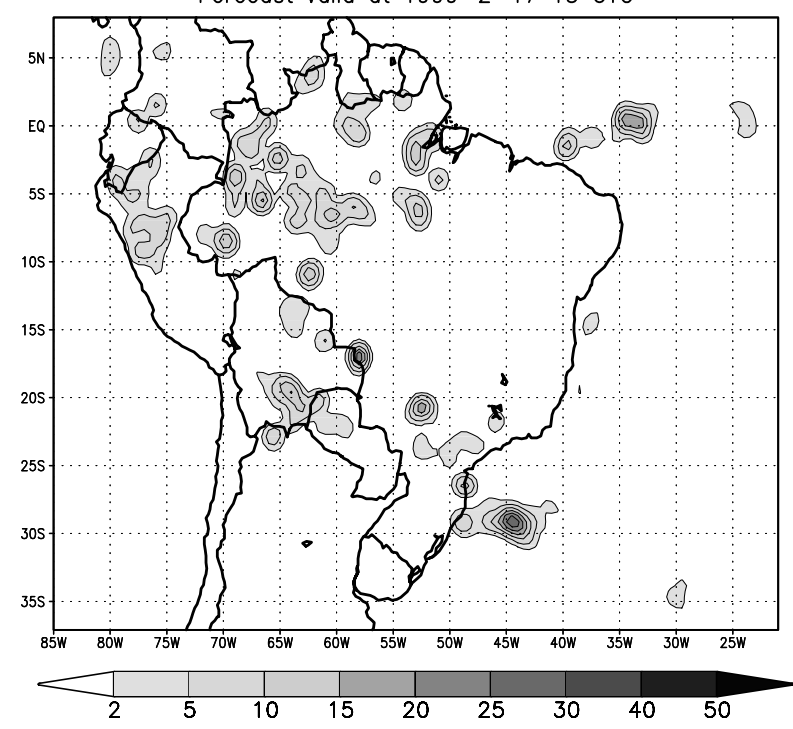

(b)

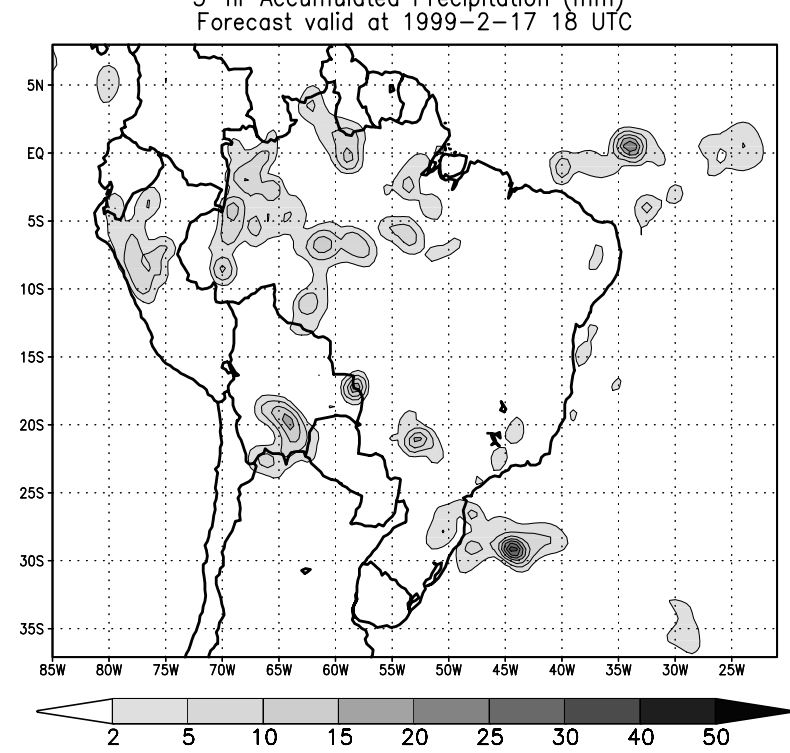

Fig. 11. FSUNRSM PI 3-h accumulated precipitation forecast (mm) valid at (a) 17 February 1999 at 15 UTC and (b) 17 February 1999 at 18 UTC, where the FSUGSM PI provided the boundary conditions.

region, but this accumulation time corresponds to the peak time of the convection over South America. The control experiments were unable to represent the most relevant precipitation patterns during the 12 -h forecast.

The PI 6-h accumulated precipitation forecast for 17 February 1999 at 18 UTC was divided into two 3-h accumulation plots where again the rainfall at the end of the initialization period was not included (Figs. 11a and b). From Figs. 10 and 11, then, we conclude that the last three hours of rainfall accumulation
(Fig. 11b) represented the expected precipitation pattern as well as the first three hours (Fig. 11a), and the PI procedure had substantial impact even after six hours as shown in Fig. 10c. These results qualify the PI procedure for being used to improve the precipitation reanalyses.

In Fig. 12, the same 24-h forecasts for the temperature fields are displayed and compared to the R-2 temperature fields. The precipitation core around $30^{\circ} \mathrm{S}$ has its displacement clearly shown by Fig. 12, particularly for the PI case (Fig. 12a). Comparing the PI plots (Figs. 12a and b) to the control (Figs. 12c and d), and the R-2 plots (Figs. 12e and f), we conclude that the forecasts of other fields besides precipitation are not degraded by using initial conditions generated by the PI scheme.

Because of the relatively poor performance of the control experiments, we sought to determine whether this was due primarily to the convection scheme used. For all cases, we performed additional experiments without PI, using a simplified ArakawaSchubert cumulus parametrization (AS) scheme (Pan and Wu, 1994). Figure 13 shows the correlation coefficients for the PI using the Kuo scheme, control with Kuo scheme, and control with AS scheme. The performance of the AS scheme was very similar to that of the Kuo without PI. Thus, the forecasting skill appears to be more closely tied to the use of precipitation assimilation than to the convection scheme used. At this time, PI has not been implemented with the AS scheme in the regional model. Treadon (1996) has incorporated PI using the AS scheme into the Medium Range Forecast (MRF) model used at NCEP.

We point out that the analysis model, the ECMWF Integrated Forecast System, uses a different convection scheme than those used here, and we may not expect models using ECMWF analyses with other convection schemes to produce the proper rain rates. A benefit of PI is that the initial state will be consistent with the convection scheme used in the forecast model.

Figure 14 illustrates the time evolution of surface pressure during the assimilation and 24-h forecast periods for a given grid point $\left[20^{\circ} \mathrm{S} ; 60^{\circ} \mathrm{W}\right]$. Four simulations are represented: the FSUGSM and the FSUNRSM using the PI procedure, and the FSUGSM and the FSUNRSM simulations where no initialization was used. The highest amplitudes present during six hours at the beginning time should be related to the problem of using analyses provided by a different model. Surface pressure oscillations are very sharp where there is no initialization, compared to initialization using the PI procedure. Due to the smaller regional model time-step (180 s), the higher-frequency oscillations can be seen. However, the oscillation amplitudes for both models remain under lower values where PI was applied. We conclude that PI produces a damping of higher frequencies. This result is similar to the results of Williamson and Temperton (1981). They compared adiabatic NNMI surface pressure with no initialization at a given grid point as well. However, the normal mode technique is a static method where the damping modes need to be predetermined. In the PI procedure, no previous knowledge 
(a) FSUNRSM + PI 24-h Forecast

(a) $850 \mathrm{hPa}$ Temperature (K) at $18 \mathrm{Feb} 1999$ 12UTC

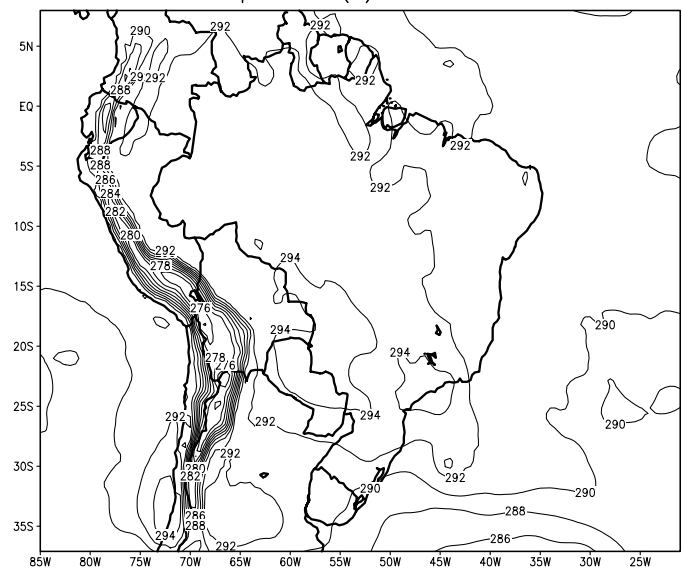

(c) FSUNRSM 24-h Forecast

(c) $850 \mathrm{hPa}$ Temperature (K) at $18 \mathrm{Feb} 1999$ 12UTC

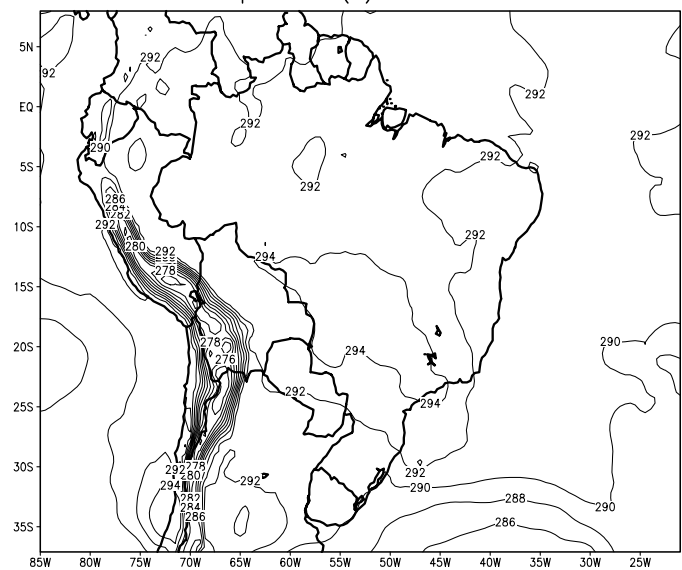

(e) NCEP-DOE Reanalysis (R-2)

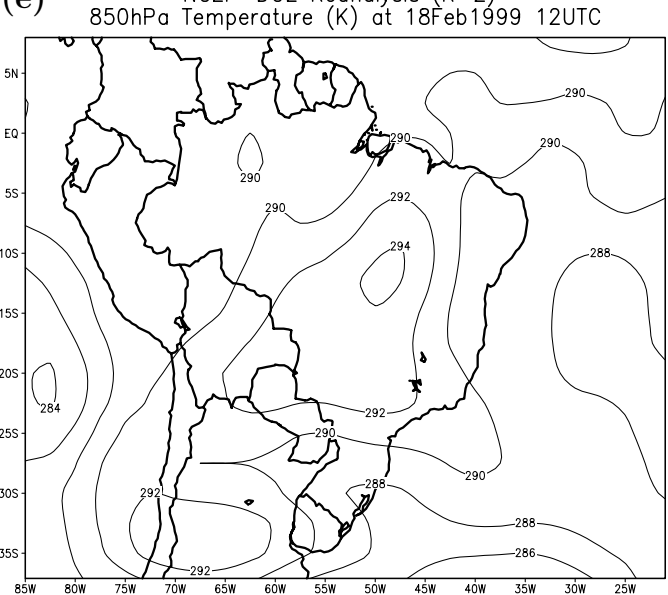

(b) FSUNRSM + PI 24-h Forecast

$300 \mathrm{hPa}$ Temperature $(K)$ at $18 \mathrm{Feb} 199912 \mathrm{UTC}$

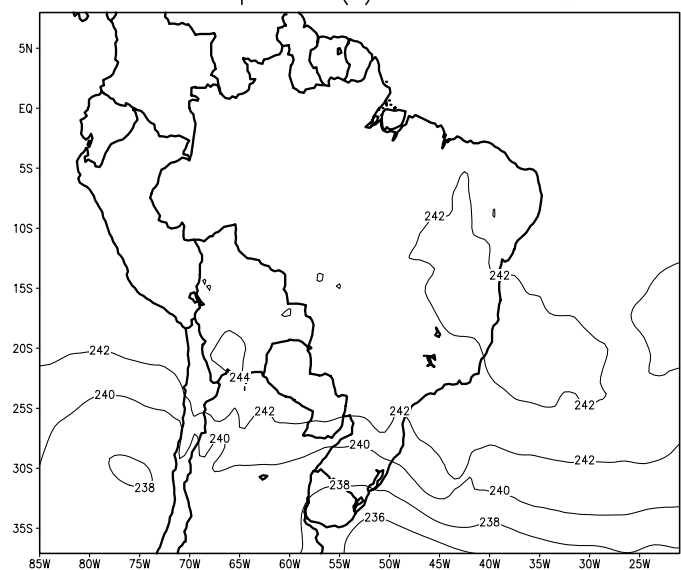

(d) FSUNRSM 24-h Forecast

(d) $30 \mathrm{hPa}$ Temperature (K) at 18Feb1999 12UTC

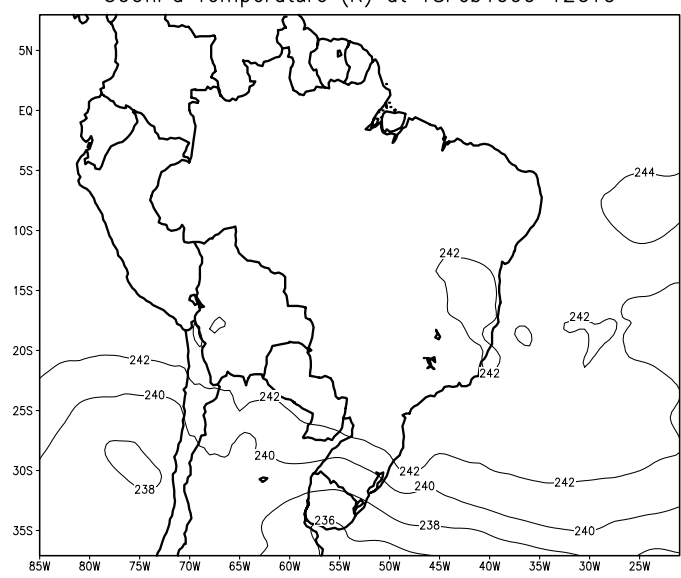

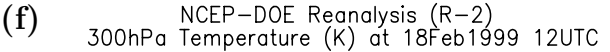

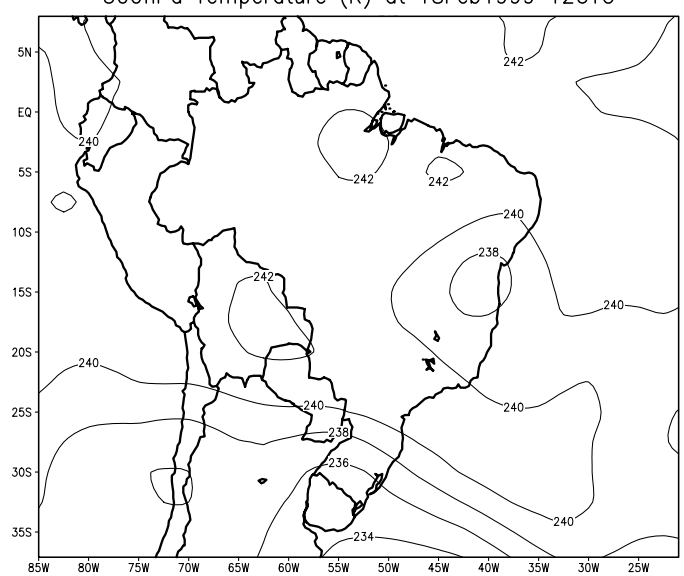

Fig. 12. Temperature (K) valid at 18 February 1999 at 12 UTC: for the FSUNRSM PI 24-h forecast at (a) $850 \mathrm{hPa}$ and (b) $300 \mathrm{hPa}$; for the FSUNRSM control experiment 24-h forecast at (c) $850 \mathrm{hPa}$ and (d) $300 \mathrm{hPa}$; and for the NCEP-DOE reanalysis (R-2) at (e) $850 \mathrm{hPa}$ and (f) $300 \mathrm{hPa}$. 


\section{4-hour Precipitation Forecast}

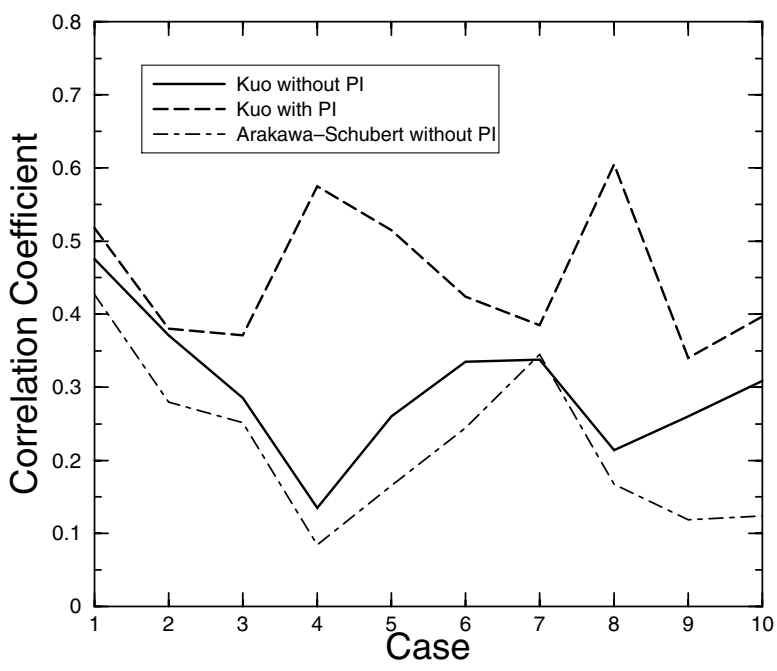

Fig. 13. Spatial correlation coefficients of 24-h accumulated precipitation forecast. Experiments using Kuo scheme without PI are represented by a solid line, Kuo scheme experiments with PI by a dashed line, and Arakawa-Schubert scheme experiments without PI by a dot-dashed line.

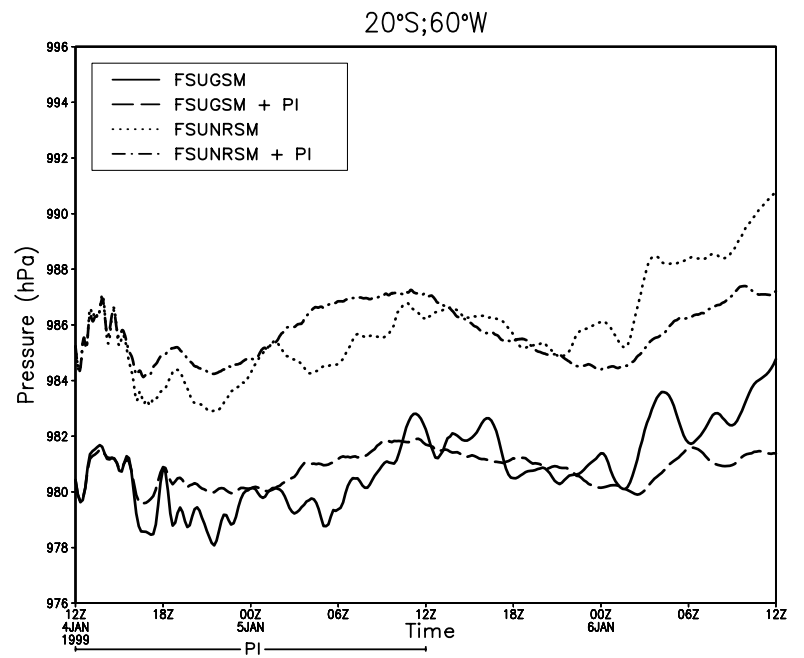

Fig. 14. Time evolution of surface pressure $(\mathrm{hPa})$ at $\left[20^{\circ} \mathrm{S} ; 60^{\circ} \mathrm{W}\right]$, starting on 4 January 1999 at 12 UTC. The FSUGSM control is represented by a solid line, FSUGSM PI by a dashed line, FSUNRSM control by a dotted line, and FSUNRSM PI by a dot-dashed line.

about which modes must be filtered is required, because during the assimilation period undesired vertical normal modes should be removed or damped by means of an adjustment obtained from primarily dynamic nudging as shown in Fig. 15, where physical nudging corresponds to rainfall and surface flux nudging together.

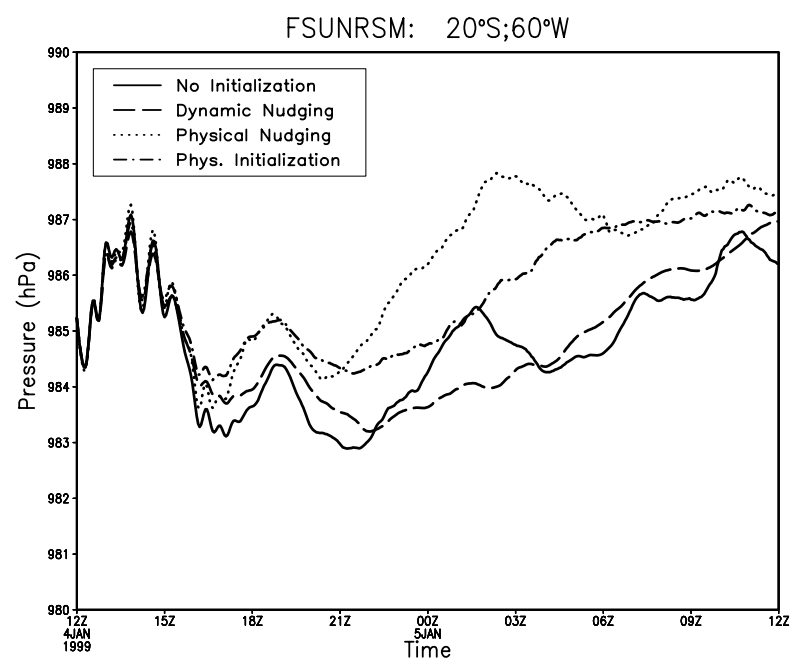

Fig. 15. Time evolution of surface pressure $(\mathrm{hPa})$ at $\left[20^{\circ} \mathrm{S} ; 60^{\circ} \mathrm{W}\right]$, during $24 \mathrm{~h}$, starting on 4 January 1999 at 12 UTC. Only the FSUNRSM is being represented ( $\Delta t=180 \mathrm{~s}$ ), where the experiments performed with PI, physical nudging, dynamic nudging and no-initialization are separately shown.

\section{Conclusion}

The implementing of the PI procedure into the FSUNRSM has shown that the model is able to assimilate the SSM/I-OLR derived rain rates. The model is able to assimilate the precipitation rather well despite the imposition of boundary conditions throughout the model domain. This assimilation is successful whether or not boundary conditions from the FSUGSM have also been physically initialized. The perturbations of the regional model are able to capture the details necessary for the assimilation. Using physically initialized boundary conditions gives better results, and this is more evident near the lateral boundaries. The initial rainfall correlation coefficients are above 0.9 , which is comparable to what has previously been reported in PI studies with the FSUGSM. The physically initialized regional state may be suitable for use as reanalysis. This study has not carefully assessed what errors may have been introduced in other model variables, such as wind. However, there is not much drift of the large-scale flow from the ECMWF analyses (not shown). Furthermore, we have made the a priori assumption that there were errors in the initial analysis, giving rise to poor initial rain rates. Despite the rainfall nudging, the temperature fields at the lower and upper levels have not been degraded compared to the control and R-2 temperature fields. Future studies will determine the impact of PI on the evolution of other fields in detail, but results from previous studies with the global model indicate that PI will be beneficial.

The 24-h forecasts using physically initialized states are better than those without, as indicated by both spatial correlation coefficients and equitable threat scores. This was true for each of the 10 selected cases. Some problems have been found with 
the model, such as erroneous precipitation in some coastal regions. These problems are more related to the simple boundary layer parametrizations than the PI procedure. A number of improvements have been made to the model since these results were obtained.

There are many areas of improvement in the PI procedure used here. As stated earlier, the model does not attempt to match rain rates when the model atmosphere is stable. Including a convective heating term to initiate convective instability would allow better rainfall matching. Another improvement would be to use higher temporal resolution satellite data during the precipitation assimilation such as the Geostationary Environmental Satellite (GOES) estimates (Nunes, 2001, 2002).

\section{Acknowledgments}

This paper forms part of the $\mathrm{PhD}$ thesis of the first author, and it was developed in collaboration with the Center for OceanAtmospheric Prediction Studies (COAPS), and the Department of Meteorology at the Florida State University (FSU) in the USA. For their support, we would like to thank: in the USA, Professors T. N. Krishnamurti and J. J. O'Brien at FSU, and Dr C. E. Williford for providing us with the atmospheric data sets used in these experiments; in Brazil, Professors P. Satyamurty, J. P. Bonatti and C. A. Nobre at the 'Centro de Previsão de Tempo e Estudos Climáticos/Instituto Nacional de Pesquisas Espaciais' (CPTEC/INPE). We would also like to thank the anonymous reviewers and, especially, Professor Alan K. Betts, for their helpful comments. This work was supported in part by the following grants: NFS ATM-9710336, NASA TRMM NAG5-4729, NOAA NA77, NOAA NA16G1365 and FAPESP 1997/11007-1 (CPTEC/INPE).

\section{References}

Anthes, R. A. 1974. Data assimilation and initialization of hurricane prediction models. J. Atmos. Sci. 31, 702-719.

Anthes, R. A., Hsie, E.-Y. and Kuo, Y.-H. 1987. Description of the Penn State/NCAR Mesoscale Model Version 4 (MM4). NCAR Technical Note NCAR/TN-282+STR. Boulder, CO, USA, 66 pp.

Aonashi, K. 1993. An initialization method to incorporate precipitation data into a mesoscale numerical weather prediction model. J. Meteorol. Soc. Japan 71, 393-406.

Arakawa, A. and Schubert, W. H. 1974. Interaction of cumulus cloud ensemble with the large-scale environment. J. Atmos. Sci. 31, 674701.

Arkin, P. A. 1979. The relationship between fractional coverage of high cloud and rainfall accumulation during GATE over the B-scale array. Mon. Wea. Rev. 107, 1382-1387.

Baer, F. and Tribbia, J. J. 1977. On complete filtering of gravity modes through nonlinear initialization. Mon. Wea. Rev. 105, 1536-1539.

Cocke, S. 1998. Case study of Erin using the FSU Nested Regional Spectral Model. Mon. Wea. Rev. 126, 1337-1346.
Cocke, S. and LaRow, T. E. 2000. Seasonal predictions using a regional spectral model embedded within a coupled ocean-atmosphere model. Mon. Wea. Rev. 128, 689-708.

Daley, R. 1991. Atmospheric data analysis (eds. J. T. Houghton, M. J. Rycroft andA. J. Dessler). Cambridge Univ. Press, Cambridge, 457 pp.

Donner, L. J. 1988. An initialization for cumulus convection in numerical weather prediction models. Mon. Wea. Rev. 116, 377-385.

Ferraro, R. R. and Marks, G. F. 1995. The development of SSM/I rainrate retrieval algorithms using ground-based radar measurements. J. Atmos. Oceanic Technol. 12, 755-770.

Fillion, L. and Errico, R. 1997. Variational assimilation of precipitation data using moist convective parametrization schemes: A 1D-Var study. Mon. Wea. Rev. 125, 2917-2942.

Gairola, R. M. and Krishnamurti, T. N. 1992. Rain rates based on SSM/I, OLR and raingauge data sets. Meteorol. Atmos. Phys. 50, 165-174.

Haase, G., Crewell, S., Simmer, C. and Wergen, W. 2000. Assimilation of radar data in mesoscale models: physical initialization and latent heat nudging. Phys. Chem. Earth (B) 25, 1237-1242.

Hamming, R. W. 1989. Digital filters. Prentice-Hall, Englewood Cliffs, NJ, 284 pp.

Heckley, W. A., Kelly, G. and Tiedtke, M. 1990. On the use of satellitederived heating rates for data assimilation within the tropics. Mon. Wea. Rev. 118, 1743-1757.

Hoke, J. E. and Anthes, R. A. 1976. The initialization of numerical models by dynamic initialization technique. Mon. Wea. Rev. 104, 15511556.

Hou, A. Y., Ledvina, D. V., Da Silva, A. M., Zhang, S. Q., Joiner, J. and Atlas, R. M. 2000. Assimilation of SSM/I-derived surface rainfall and total precipitation water for improving the GEOS analysis for climate studies. Mon. Wea. Rev. 128, 509-537.

Huang, X. Y. and Lynch, P. 1993. Diabatic digital-filtering initialization - application to the HIRLAM model. Mon. Wea. Rev. 121, 589-603.

Huang, X. Y., Cederskov, A. and Kallen, E. 1994. A comparison between digital filtering initialization and nonlinear normal-mode initialization in a data assimilation system. Mon. Wea. Rev. 122, 1001-1015.

Kanamitsu, M. 1975. On numerical prediction over a global tropical belt. Report No. 75-1, 282 pp. (Available from the Dept. of Meteorology, FSU, Tallahassee, FL, USA.)

Kanamitsu, M., Wesley, E., Woollen, S.-K. Yang, Hnilo, J. J., Fiorino, M. and Potter, G. L. 2002. NCEP-DOE AMIP-II reanalysis (R-2). Bull. Am. Meteorol. Soc. 83, 1631-1643.

Kasahara, A., Mizze, A. P. and Donner, L. J. 1994. Diabatic initialization for improvement in the tropical analysis of divergence and moisture using satellite radiometric imagery data. Tellus 46A, 242-264.

Kitade, T. 1983. Non-linear normal mode initialization with physics. Mon. Wea. Rev. 11, 2194-2213.

Krishnamurti, T. N., Low-Nam, S. and Pasch, R. 1983. Cumulus parametrization and rainfall rates II. Mon. Wea. Rev. 111, 815-828.

Krishnamurti, T. N., Ingles, K., Cocke, S., Pasch, R. and Kitade, T. 1984. Details of low latitude medium range numerical weather prediction using a global spectral model II. Effect of orography and physical initialization. J. Meteorol. Soc. Japan 62, 613-649.

Krishnamurti, T. N., Bedi, H. S., Heckley, W. and Ingles, K. 1988. Reduction of the spinup time for evaporation and precipitation in a spectral model. Mon. Wea. Rev. 116, 907-920. 
Krishnamurti, T. N., Xue, J., Bedi, H. S., Ingles, K. and Oosterhof, D. 1991. Physical initialization for numerical weather prediction over the tropics. Tellus 43AB, 53-81.

Krishnamurti, T. N., Bedi, H. S. and Ingles, K. 1993. Physical initialization using SSM/I rain rates. Tellus 45A, 247-269.

Krishnamurti, T. N., Rohaly, G. D. and Bedi, H. S. 1994. On the improvement of precipitation forecast skill from physical initialization. Tellus 46A, 598-614.

Krishnamurti, T. N., Bhowmik, S. K. R., Oosterhof, D. and Rohaly, G. D. 1995. Mesoscale signatures within the tropics generated by physical initialization. Mon. Wea. Rev. 123, 2771-2790.

Kuo, H. L. 1974. Further studies of the parametrization of the influence of cumulus convection on large-scale flow. J. Atmos. Sci. 31, 1232-1240.

Lewis, J. M. and Deber, J. C. 1985. The use of adjoint equation to solve variational adjustment problem with advective constraints. Tellus $37 \mathrm{~A}$, 309-322.

Lynch, P. and Huang, X. Y. 1992. Initialization of the HIRLAM model using a digital-filter. Mon. Wea. Rev. 120, 1019-1034.

Lynch, P. and Huang, X. Y. 1994. Diabatic initialization using recursive filters. Tellus 46A, 583-597.

Lynch, P., Giard, D. and Ivanovici, V. 1997. Improving the efficiency of a digital filtering scheme for diabatic initialization. Mon. Wea. Rev. 125, 1976-1982.

Machenhauer, B. 1976. An initialization procedure based on the elimination of gravity oscillations in a spectral barotropic primitive equation model. Ann. Meteorol. 11, 135-138.

Machenhauer, B. 1977. On the dynamics of gravity oscillations in a shallow water model with applications to normal mode initialization. Beitr. Phys. Atmos. 50, 253-271.

Manobianco, J., Koch, S., Karayampudi, V. M. and Negri, A. J. 1994. The impact of assimilating satellite-derived precipitation rates on numerical simulations of the ERICA IOP 4 cyclone. Mon. Wea. Rev. 122, 341-365.

Marècal, V. and Mahfouf, J.-F. 2000. Variational retrieval of temperature and humidity profiles from TRMM precipitation data. Mon. Wea. Rev. 128, 3853-3866.

Navon, I. M., Zou, X., Derber, J. and Sela, J. 1992. Variational data assimilation with an adiabatic version of the NMC spectral model. Mon. Wea. Rev. 120, 1433-1446.

Nunes, A. M. B. 2001. Assimilation of rain rates using satellite data by a regional spectral model. Proc. 9th Conference on Mesoscale Processes, Fort Lauderdale, FL, USA, 226-227.

Nunes, A. M. B. 2002. Physical initialization in weather prediction models and a study of its effects on the energy partition in the vertical and horizontal modes over the tropics and South America. (In Portuguese). PhD Thesis. Available from INPE, S. J. Campos, SP, Brazil, 220 pp.

Pan, H.-L. and Wu, W. S. 1994. Implementing a mass flux convection parametrization package for the NMC MRF model. Proc. 10th Conference on Numerical Weather Prediction, Portland, OR. American Meteorological Society, Washington, DC, 96-98.

Polavarapu, S., Tanguay, M. and Fillion, L. 2000. Four-dimensional variational data assimilation with digital filter initialization. Mon. Wea. Rev. 128, 2491-2510.

Puri, K. and Miller, M. J. 1990. The use of satellite data in the specification of convective heating for diabatic initialization and moisture adjustment in numerical weather prediction. Mon. Wea. Rev. 118, 6793.

Puri, K. and Davidson, N. E. 1992. The use of infrared satellite cloud imagery as proxy data for moisture and diabatic heating in data assimilation. Mon. Wea. Rev. 120, 2329-2341.

Ramamurthy, M. K. and Carr, F. H. 1987. Four-dimensional data assimilation in the monsoon region. Part I: Experiments with wind data. Mon. Wea. Rev. 115, 1678-1706.

Sasaki, Y. 1970. Numerical variational analysis with weak constraint and application to surface analysis of severe storm gust. Mon. Wea. Rev. 98, 899-910.

Schaefer, J. T. 1990. The critical success index as an indicator of warning skill. Wea. Forecasting 5, 570-575.

Treadon, R. E. 1996. Physical initialization in the NMC global data assimilation system. Meteorol. Atmos. Phys. 60, 57-86.

Tsuyuki, T. 1997. Variational data assimilation in the tropics using precipitation data. Part III: Assimilation of SSM/I precipitation rates. Mon. Wea. Rev. 125, 1447-1464.

Williamson, D. L. 1976. Normal mode initialization procedure applied to forecasts with the global shallow water equations. Mon. Wea. Rev. 104, 195-206.

Williamson, D. L. and Temperton, C. 1981. Normal mode initialization for a multilevel grid-point model. Part II: Non-linear aspects. Mon. Wea. Rev. 109, 745-757.

Yap, K. -S. 1995. Impact of Newtonian assimilation and physical initialization on the initialization and prediction by a tropical mesoscale model. Mon. Wea. Rev. 123, 833-861.

Zou, X. and Kuo, Y.-H. 1996. Rainfall assimilation through an optimal control of initial and boundary conditions in a limited-area mesoscale model. Mon. Wea. Rev. 124, 2859-2882.

Županski, D. and Mesinger, F. 1995. Four-dimensional variational assimilation of precipitation data. Mon. Wea. Rev. 123, 11121127. 